\title{
Thyroid Disorders
}

\begin{abstract}
N P Somasundaram, M Sumanatilleke, P Katulanda, C Garusinghe, S Abhayarathna, S Pathmanathan, S S C Gunathilake, C J Subhasinghe, A M Wijesinghe, M Arambewela, M D S A Dilrukshi, R U Vithiya, I Ranathunga, P S A Wijewickrama, H A Dissanayake, A M N L de Silva, N Yogendranathan, C A Jayasuriya, W M U A Wijetunga, K K K Gamage
\end{abstract}

Copyright: This is an open-access article distributed under the terms of the Creative Commons Attribution License, which permits unrestricted use, distribution, and reproduction in any medium, provided the original author and source are credited (CC BY 4.0)

\section{Disclaimer:}

Clinical Practice Guidelines are developed to be of assistance to health care professionals by providing guidance and recommendations for particular areas of practice. The Guidelines should not be considered inclusive of all proper approaches or methods, or exclusive of others. The Guidelines cannot guarantee any specific outcome, nor do they establish a standard of care. The Guidelines are not intended to dictate the treatment of a particular patient. Treatment decisions must be made based on the independent judgment of health care providers and each patient's individual circumstances.

The Sri Lanka College of Endocrinologists makes no warranty, express or implied, regarding the Guidelines and specifically excludes any warranties of merchantability and fitness for a particular use or purpose. The college shall not be liable for direct, indirect, special, incidental, or consequential damages related to the use of the information contained herein.

\section{Abbreviations}

AF

AITD autoimmune thyroid diseases

ART assisted reproductive technology

ATD anti-thyroid drugs

BB beta blocker

BMD bone mineral density

CCB calcium channel blocker

CHD coronary heart disease

CVD cardiovascular disease

DXA dual-energy X-ray absorptiometry

FSH follicular stimulating hormone

FT3 free triiodothyronine

FT4 free thyroxine

G-CSF granulocyte colony stimulating factor

GAG glycosaminoglycans

GC glucocorticoids

GD Graves disease

GO Graves orbitopathy

hCG human chorionic gonadotrophin

HPT hypothalamo-pituitary thyroid axis

LFT liver function tests

LH luteinizing hormone

LT4 levothyroxine

LDL low density lipoprotein

MNG multi-nodular goitre
NAFLD non-alcoholic fatty liver disease

NSAIDs non-steroidal anti-inflammatory drugs

$\mathrm{OH}$ overt hypothyroidism

PR pregnancy-specific reference range

PTU propylthiouracil

QoL quality of life

RAI radioactive iodine

SERM Selective oestrogen receptor modulator

SH subclinical hypothyroidism

STN solitary thyroid nodule

TA toxic adenoma

TBG thyroxine binding globulin

TFT thyroid function tests

TH thyroid hormone

TIRADS Thyroid Imaging Reporting and Data System

TPO thyroid peroxidase

TRAb TSH receptor antibodies

TRH thyrotropin-releasing hormone

TSH thyroid stimulating hormone

TSHR TSH receptor

TT3 total triiodothyronine

TT4 total thyroxine

TTR transthyretin

ULN upper limit of normal 


\section{INTRODUCTION}

Thyroid hormones (TH) play a vital role in the normal growth and metabolism. Thyroid disorders can have a significant impact on wellbeing and quality of life (QoL) of individuals and on the healthcare system of the country. Therefore, evidence based, up to date guidelines on investigation and management of these disorders, adapted to the local setting are a timely requirement.

Thyroid disorders can present with hypofunction or hyperfunction of the gland, as well as benign or malignant thyroid nodules. Focus of this clinical practice guideline is on hypothyroidism and thyrotoxicosis.

\subsection{Epidemiology}

\section{Global situation}

Global distribution of thyroid disorders varies based on several factors, including gender, iodine status, predisposition to autoimmunity, smoking, alcohol consumption and genetic factors. Overall, thyroid disorders are more common among females. Nodular thyroid disorders are more frequently found in iodine deficient areas, while autoimmune thyroid disorders are common in iodine replete areas (1).

\section{Hypothyroidism}

Iodine deficiency and thyroid autoimmunity (Hashimoto thyroiditis) are the commonest causes for hypothyroidism. In iodine sufficient areas, prevalence of overt hypothyroidism is $1-2 \%$ and is 10 times commoner among females than males, with an increasing prevalence with age (2). Worldwide annual incidence of Hashimoto thyroiditis is estimated to be $0.3-1.5$ cases per 1000 persons (2)(3).

\section{Hyperthyroidism}

Overall prevalence of hyperthyroidism is estimated to be $1.3 \%$ and incidence is $2.7 \%$ in females and $0.7 \%$ in males (4)(5). Graves disease (GD) is the most common cause for hyperthyroidism, followed by toxic multi-nodular goitre (MNG) (4). GD contributes to $70-80 \%$ of all cases of hyperthyroidism in iodine sufficient countries while in iodine deficient countries it contributes to $50 \%$ of all cases (6)(7). Toxic MNG and solitary toxic nodule (STN) are more prevalent in iodine deficient areas.

\section{Thyroid dysfunction in pregnancy}

The prevalence of overt hypothyroidism, subclinical hypothyroidism and isolated hypothyroxinaemia during pregnancy is $0.5 \%, 3.5 \%$ and $2.1 \%$ respectively in the west (8). Estimated incidence of overt thyrotoxicosis in pregnancy is $0.2 \%$ and subclinical thyrotoxicosis is $2.5 \%$ (8). GD is the most common cause for thyrotoxicosis in pregnancy.

\section{Sri Lankan situation}

Prior to 1995, high prevalence of iodine deficiency in Sri Lanka made the country endemic for goitres. Universal iodization of salt (initiated in 1995) was successful in overcoming this situation, resulting in a reduction of goitre prevalence in Sri Lanka from $18.2 \%$ in 1986 to $3.8 \%$ in 2005. The prevalence of autoimmune thyroid diseases (AITDs) was found to be between $16-20 \%$ (9). In a regional study done in 2014 , thyroid dysfunction was present in $21.1 \%$ of patients with type 2 diabetes (subclinical hypothyroidism: $9.4 \%$, overt hypothyroidism: 6.1\%) (10).

\subsection{Thyroid physiology}

\section{Regulation of TH production and secretion}

TH biosynthesis [Figure 1.1.(a)] and secretion are under tight control of hypothalamo-pituitary-thyroid (HPT) axis [Figure 1.1.(b)].

\section{Transport of THs in blood}

THs circulate mainly in the bound form (more than 99.95\% of T4 and $99.5 \%$ of T3) (Table 1.1). Alterations in serum levels of these proteins, mainly TBG can alter serum total T4 and T3 (TT4 and TT3) concentrations, without an effect on free hormone (FT4 and FT3) concentrations (11) (Table1.2).

\section{Action of THs}

Actions of THs are mediated by binding to $\alpha$ and $\beta$ T3 nuclear receptors, exerting genomic effects. These hormonal actions are important for brain and somatic development in neonates, metabolic functions, bone development and cardiac function in adults.

\section{Thyroid function tests (TFT)}

Thyroid functions are assessed by following tests (Table 1.3) 
(a)

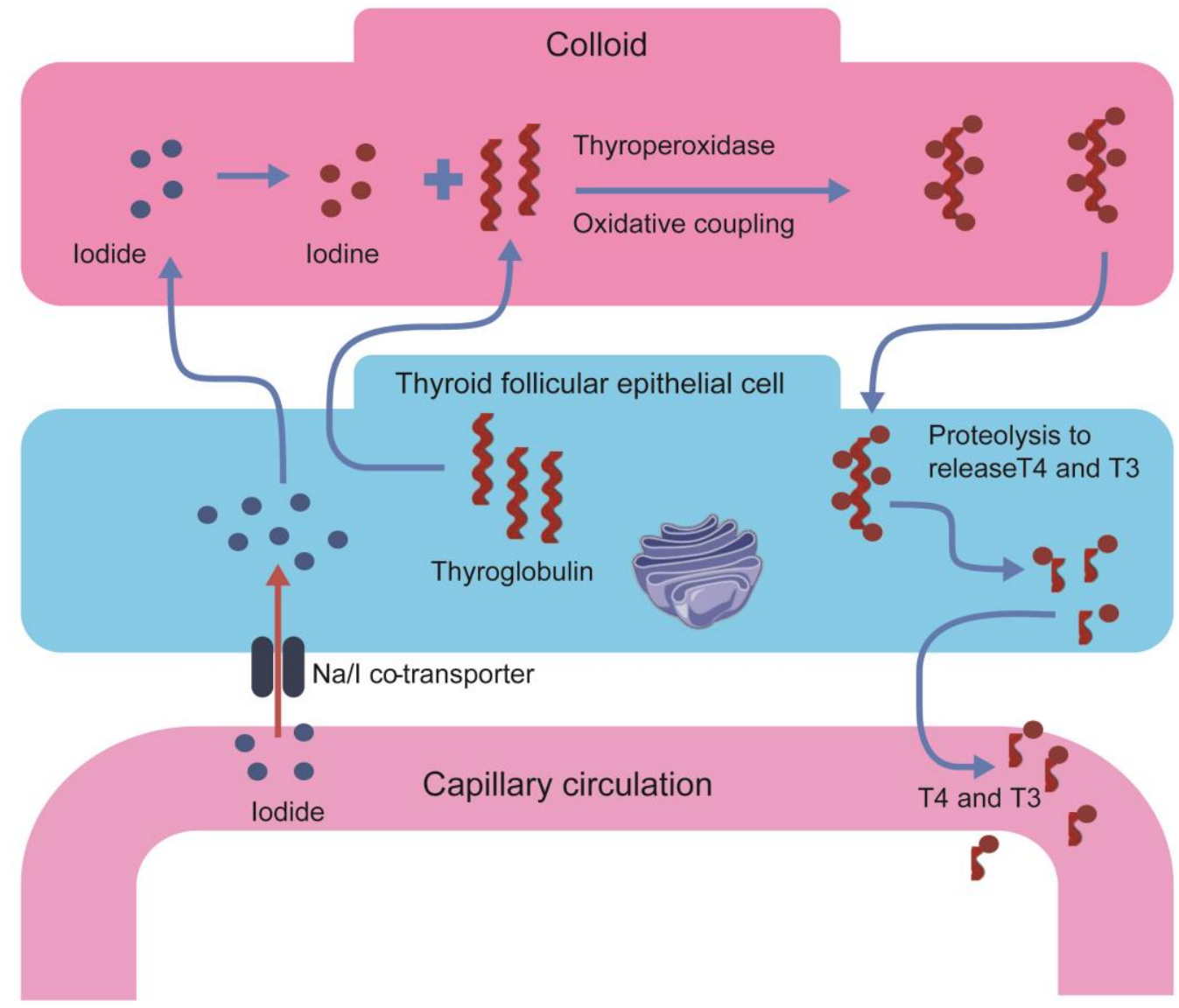

(b)

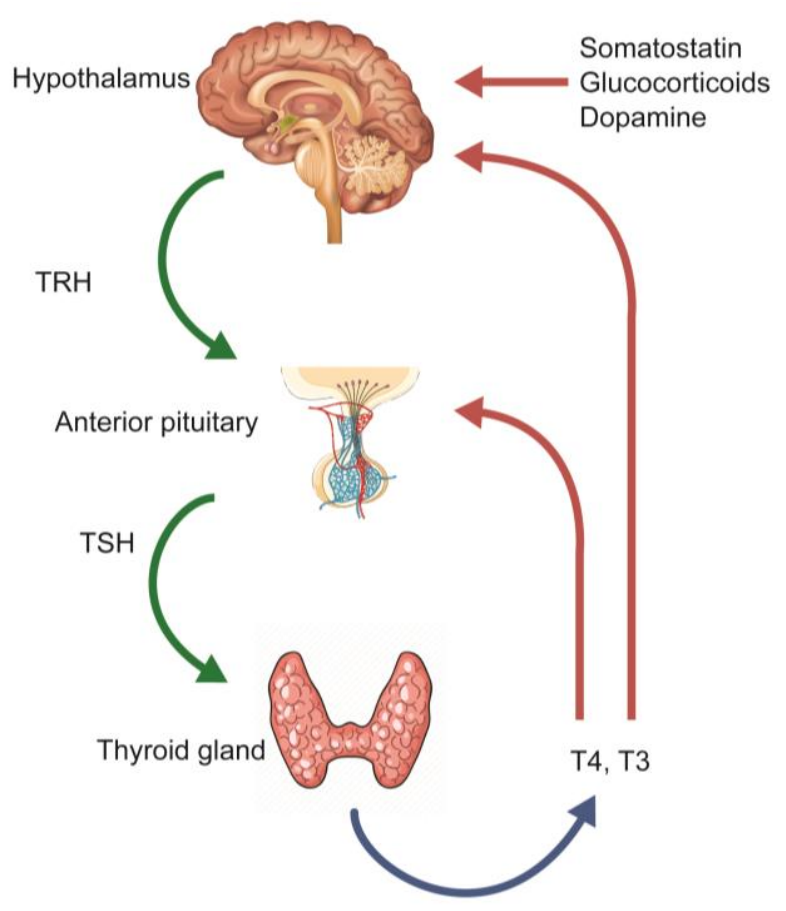

Figure 1.1.

(a) TH biosynthesis. Thyroxine (T4) and 3,5,3'triiodothyronine (T3) are the 2 biologically active thyroid hormones. Iodine is essential for thyroid hormone synthesis. T4 is produced at a rate of $80-100 \mu \mathrm{g}$ per day by the thyroid. T3 is mainly produced by extra-thyroidal deiodination $(80 \%)$

(b) Regulation of TH Red arrows: inhibitory signal, green arrows: stimulatory signal. TRH: thyrotropin releasing hormone, TSH: thyroid stimulating hormone, T3: tri-iodothyronine, T4: tetra-iodothyronine (thyroxine) Note: TSH has 2 subunits; $\alpha$ and $\beta$. $\alpha$-subunit is similar to LH, FSH and hCG and $\beta$-subunit is unique to TSH 
Table 1.1. Transport of TH and binding proteins

\begin{tabular}{lll}
\hline Type of protein & $\begin{array}{l}\text { Percentage of T4 } \\
\text { bound }\end{array}$ & $\begin{array}{l}\text { Percentage of T3 } \\
\text { bound }\end{array}$ \\
\hline Thyroxine binding globulin (TBG) & $75 \%$ & $80 \%$ \\
Transthyretin (TTR) & $10 \%$ & $5 \%$ \\
Albumin & $12 \%$ & $15 \%$ \\
\hline
\end{tabular}

Table 1.2. Factors altering TBG levels and TH binding

\begin{tabular}{lll}
\hline Elevated TBG & Suppressed TBG & $\begin{array}{l}\text { Factors inhibiting the binding } \\
\text { to proteins }\end{array}$ \\
\hline Pregnancy & Androgens & Salicylates \\
High oestrogen level & Anabolic steroids & $\begin{array}{l}\text { Frusemide } \\
\text { Phenytoin }\end{array}$ \\
Hepatitis & Glucocorticoids & Carbamazepine \\
Porphyria & Severe illness & NSAIDs \\
Heroin & Liver failure & Heparin \\
Methadone & Nicotinic acid & \\
Mitotane & & \\
5 - fluorouracil & & \\
Selective oestrogen receptor & & \\
modulators (SERMs) & & \\
\hline
\end{tabular}

\section{Table 1.3. Considerations for interpretation of thyroid functions}

\begin{tabular}{ll}
\hline Test & Considerations \\
\hline TSH & Upper limit of the normal range of TSH increases with age. \\
& TSH secretion follows a circadian rhythm, with highest levels in early morning, and lowest in late \\
& afternoon, causing only slight variations of TSH by $0.95 \mathrm{mIU} / \mathrm{ml}$ to $2 \mathrm{mIU} / \mathrm{ml}$ and does not necessarily \\
& reflect a change in thyroid status (12)(13). \\
& Assay interferences can occur with the heterophile antibodies leading to either falsely elevated or \\
& suppressed TSH values. E.g.: Graves disease, sero-positive rheumatoid arthritis (13). \\
& TSH level correlates positively with body mass index (BMI). Morbid obesity is associated with high TSH \\
& levels (14). \\
& Biotin can cause falsely low TSH values. Stop 2 days before the assay. \\
& Affected by TBG level and its binding to T4 and T3 (Table 1.2) \\
TT4, TT3 & $\begin{array}{l}\text { Measures unbound fraction and therefore is unaffected by alterations of binding to proteins. } \\
\text { FT4, FT3 }\end{array}$ \\
& Biotin can cause falsely high values in FT4 and FT3 measurements. Stop biotin for 2 days prior to the \\
& test (15).
\end{tabular}




\section{HYPOTHYROIDISM}

\subsection{Introduction}

Hypothyroidism is a syndrome that results from abnormally low secretion of THs from the thyroid gland, leading to a decrease in basal metabolic rate and multisystem dysfunction. The most severe form is known as myxoedema.

\subsection{Causes of hypothyroidism}

Hypothyroidism may be primary, secondary or tertiary due to thyroid disease, pituitary disease, or hypothalamic dysfunction respectively. Primary hypothyroidism can be overt or subclinical (table 2.1)

\section{Table 2.1. Classification of primary hypothyroidism}

\begin{tabular}{ll}
\hline Overt hypothyroidism $(\mathrm{OH})$ & Elevated TSH with sub-normal FT4 \\
\hline Subclinical hypothyroidism $(\mathrm{SH})$ & $\begin{array}{l}\text { TSH above the upper reference limit and a normal FT4 } \\
\begin{array}{l}\text { Note: This is only applicable when thyroid function has been stable for } 3 \text { months or } \\
\text { more, the hypothalamo-pituitary function is normal, and there is no recent or on-going } \\
\text { severe illness }\end{array}\end{array}$ \\
\hline
\end{tabular}

\subsubsection{Causes of primary hypothyroidism}

These causes are summarised in table 2.2

\section{Table 2.2. Causes of primary hypothyroidism}

\begin{tabular}{ll}
\hline Congenital & Thyroid agenesis / dysplasia \\
& Defects in thyroid hormone synthesis \\
\hline Acquired & Chronic autoimmune thyroiditis / Hashimoto's thyroiditis \\
& Post-thyroidectomy \\
& Iodine deficiency \\
& Post radio-iodine thyroid ablation \\
& External beam radiotherapy for non-thyroidal head and neck malignancy \\
& Drugs inhibiting the synthesis or release of thyroxine - Lithium, iodide, over treatment of \\
& hyperthyroidism \\
& Infiltrative diseases - e.g.: sarcoidosis
\end{tabular}

\section{Autoimmune thyroid diseases (AITDs)}

- Auto-immunity against the thyroid leads to two distinct pathogenic processes with opposing clinical outcomes: hypothyroidism in Hashimoto's thyroiditis and hyperthyroidism in GD (except when TSH receptor antibodies have inhibitory effects, where hypothyroidism results)
- Pathogenesis and risk factors of AITD are illustrated in Figure 2.1 and 2.2 respectively.

- Many patients with autoimmune thyroid disease are biochemically euthyroid, but $75 \%$ of them harbour circulating anti-thyroid antibodies, the presence of which predicts progression to hypothyroidism (16). 


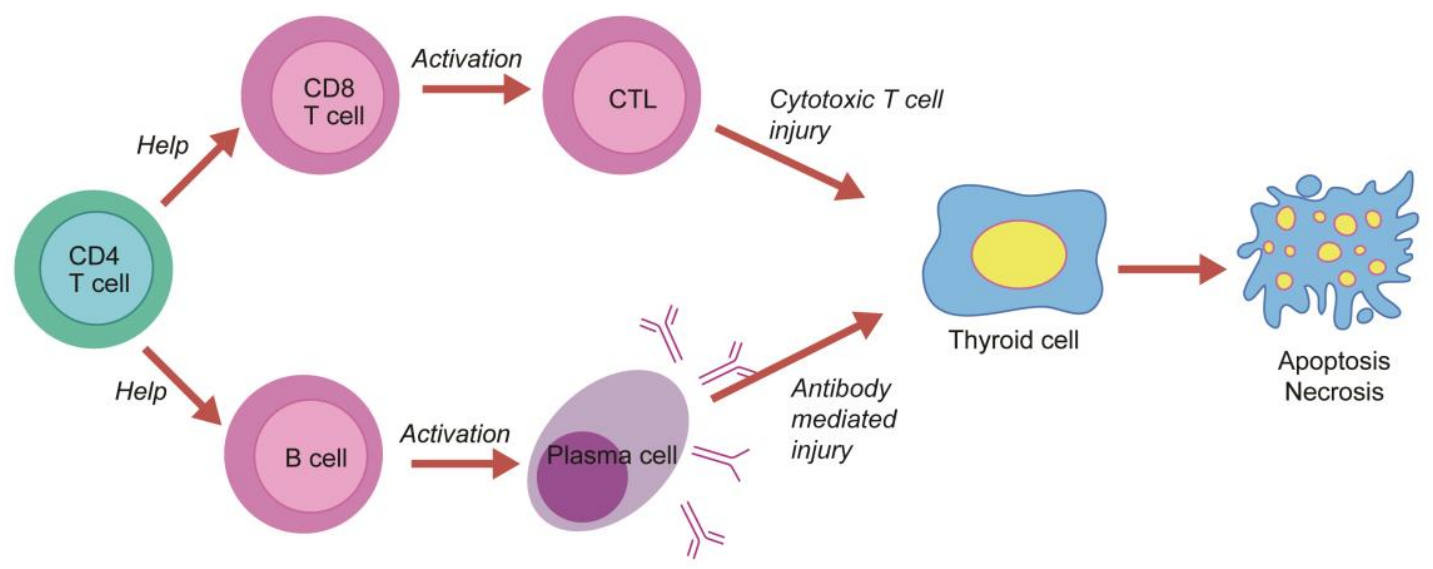

Figure 2.1. Pathogenesis of Hashimoto's thyroiditis (17).

Dysregulation of humoral and cell mediated immune responses leads to destruction of thyroid cells over time.

Presence of circulating antibodies predicts progression to overt hypothyroidism

\subsubsection{Central hypothyroidism (Secondary and tertiary hypothyroidism)}

Hypothalamic or pituitary diseases result in central hypothyroidism. In this condition TSH level may be low or inappropriately normal for the level of FT4 and therefore not a useful monitoring marker when thyroxine replacement is started. FT4 levels should be maintained within the upper half of the reference range when treating central hypothyroidism.

\subsection{Diseases associated with hypothyroidism}

Several autoimmune diseases and genetic / congenital syndromes are associated with hypothyroidism (table 2.3).

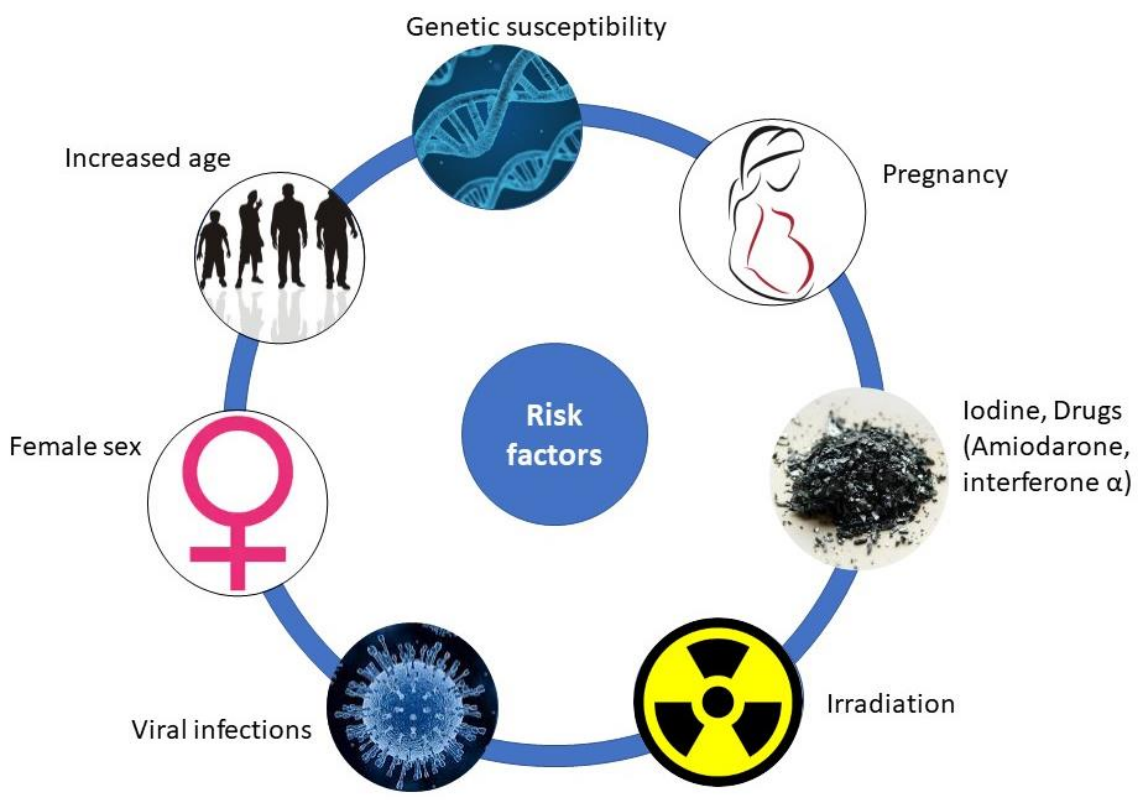

Figure 2.2. Risk factors for Hashimoto's thyroiditis (2), (5), (18), (19), (20), (21), and (22) 


\section{Table 2.3. Diseases and syndromes associated with hypothyroidism (18)}

\begin{tabular}{ll}
\hline Associated autoimmune diseases & Other associated syndromes \\
\hline Vitiligo & Pendred syndrome \\
Addison disease & Down syndrome \\
Type 1 diabetes mellitus & Turner syndrome \\
Rheumatoid arthritis & Bamforth-Lazarus syndrome \\
Chronic autoimmune gastritis & Brain-lung-thyroid syndrome \\
Pernicious anaemia & \\
Systemic lupus erythematosus & \\
Ulcerative colitis & \\
Multiple sclerosis & \\
Psoriatic arthritis & \\
Myasthenia gravis & \\
Coeliac disease & \\
\hline
\end{tabular}

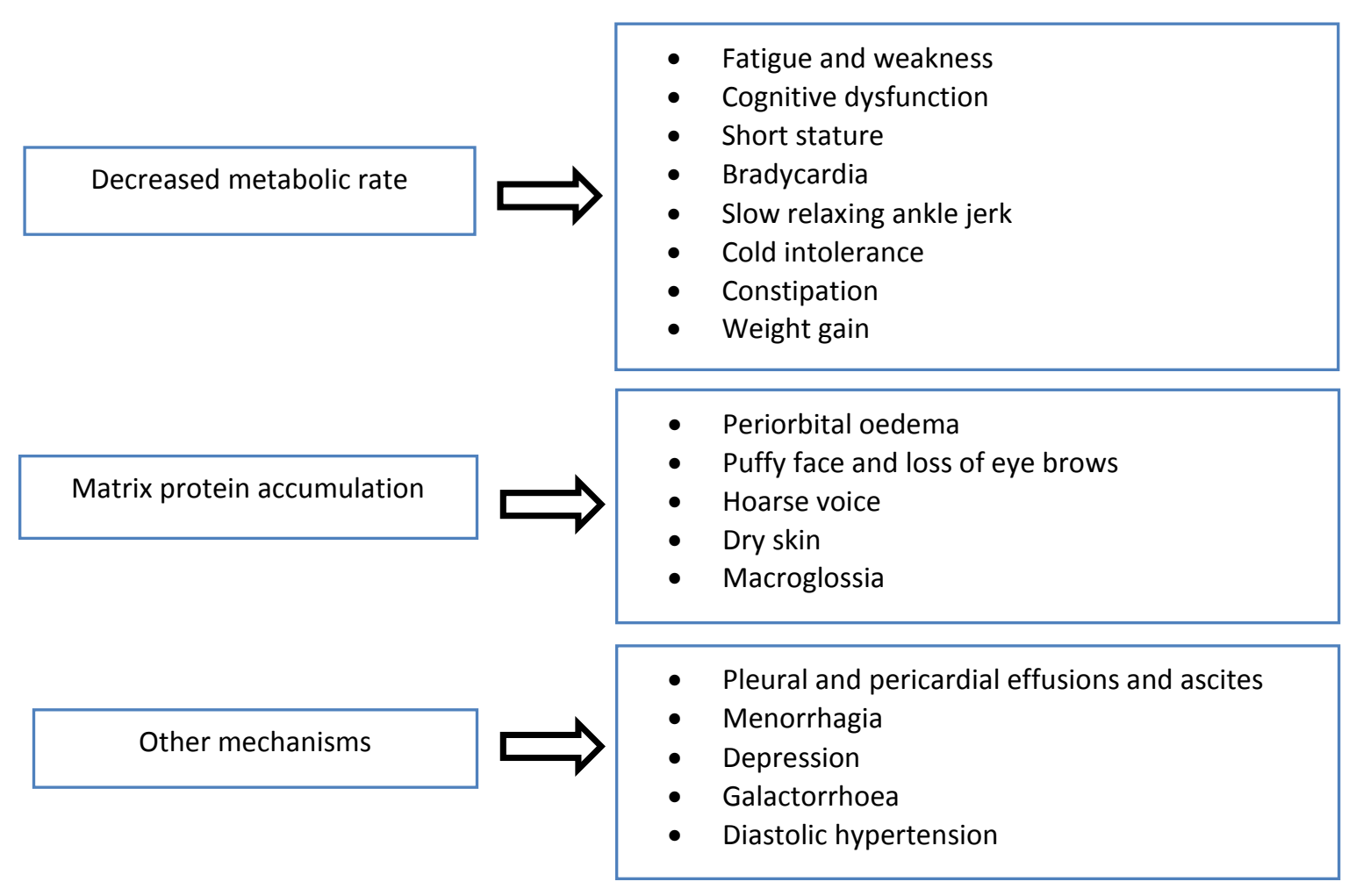

Figure 2.3. Symptoms and signs of hypothyroidism (19) 


\subsection{Clinical features of hypothyroidism}

The symptoms and signs of hypothyroidism (figure 2.3) depend on the severity of TH deficiency and the rapidity at which it occurs. Associated hypogonadism and adrenal insufficiency in central hypothyroidism may mask the manifestations of hypothyroidism.

\subsection{Evaluation of hypothyroidism}

Evaluation for hypothyroidism should be done in all patients presenting with clinical features of hypothyroidism or in special situations which are mentioned in box 2.1 (20)(21).

\subsubsection{Diagnosis of hypothyroidism}

Due to the lack of specificity of the clinical manifestations, the diagnosis of hypothyroidism is based primarily upon TFTs which include TSH and FT4.
It is recommended to use local laboratory reference range when interpreting TFTs.

Note: If an abnormal thyroid function report is not compatible with the clinical presentation, the test should be repeated.

Elevated TSH and normal FT4 should be demonstrated on at least 2 occasions, 3 months apart to diagnose subclinical hypothyroidism.

\subsubsection{Supportive tests for evaluation of hypothyroidism}

Supportive tests (Table 2.4) are used to identify the aetiology and complications of hypothyroidism.

Box 2.1. Special situations to suspect hypothyroidism

1. Personal risk factors

- Strong family history of hypothyroidism

- Newborns of mothers with thyroid diseases (In Sri Lanka all the newborn babies are screened with heel prick TSH test)

- Past history of neck irradiation, RAI, thyroid surgery

- Patients on drugs such as lithium, amiodarone

- Patients with other autoimmune diseases

2. Patients with a goitre

3. Associated syndromes - Turner syndrome, Down syndrome (table 2.3)

4. Abnormal biochemistry

- Substantial hyperlipidaemia

- Unexplained hyponatraemia

- High serum creatine kinase

- Macrocytic anaemia

5. Associated clinical conditions

- Pericardial or pleural effusions

- Pituitary or hypothalamic disorders 


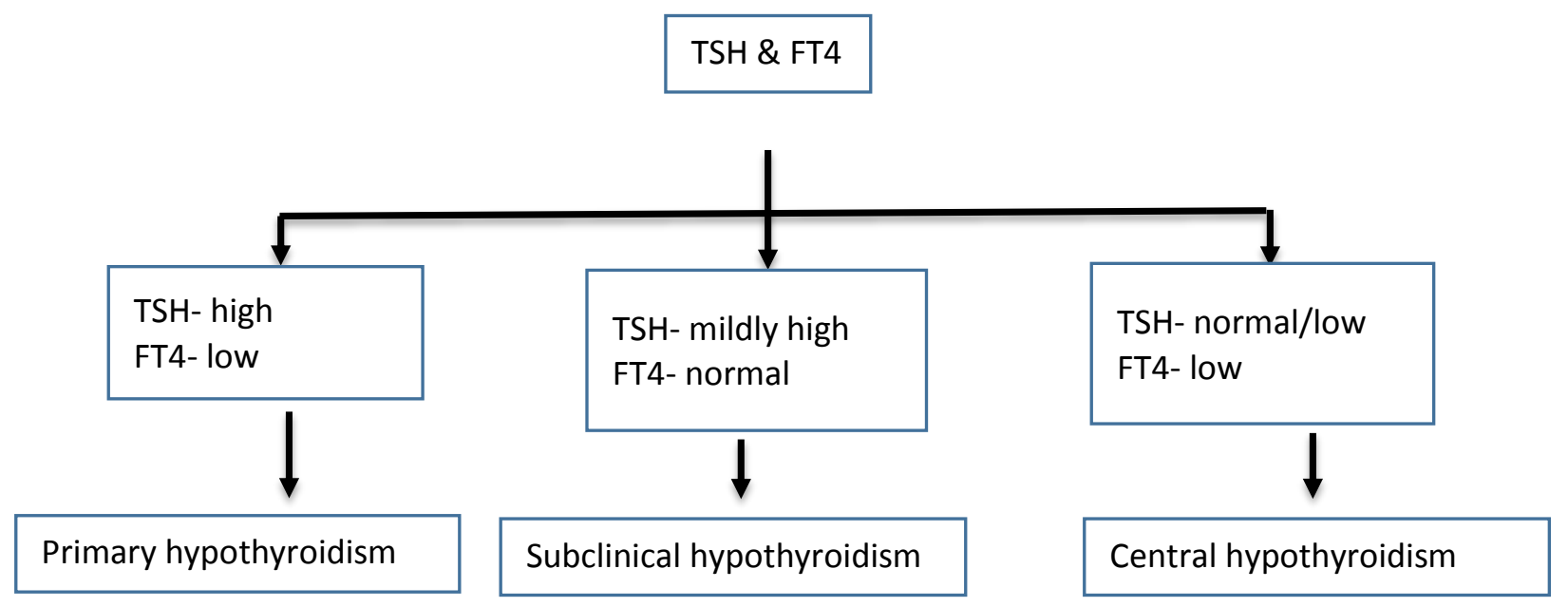

Figure 2.4. Diagnosis of hypothyroidism

\section{Table 2.4. Supportive tests for evaluation of hypothyroidism}

\begin{tabular}{ll}
\hline Supportive tests & Expected results \\
\hline Ultrasound scan of thyroid & $-\quad$ To evaluate the goitre if present \\
& $-\quad$ Look for nodularity / diffuse enlargement \\
& $-\quad$ If nodule present, determine the TIRADS score for risk stratification \\
Thyroid peroxidase (TPO) & Elevated in over $90 \%$ of patients with autoimmune thyroiditis, the most common cause of \\
antibodies & primary hypothyroidism.
\end{tabular}

TIRADS: Thyroid Imaging Reporting and Data System - a scoring system to stratify risk of malignancy based on ultrasound appearance

\subsection{Management of hypothyroidism}

All the patients diagnosed with overt hypothyroidism will require levothyroxine (LT4) replacement.

\subsubsection{Initiation of levothyroxine replacement}

- LT4 is the mainstay of treatment since biologically active $\mathrm{T} 3$ is generated by the peripheral conversion of LT4 (20).

- $\quad$ The dose can range from 50 to $\geq 200 \mu \mathrm{g} /$ day (see table for exceptions). Lower doses (e.g. 25$50 \mu \mathrm{g} /$ day) will be required in milder degrees of hypothyroidism; for example, if the serum TSH is $<10 \mathrm{mIU} / \mathrm{L}$ or if the patient has subclinical hypothyroidism.

- Starting dose of levothyroxine is decided based on individual characteristics of the patient (20).

The usual starting dose of LT4 is $1.6-1.8 \mu \mathrm{g} / \mathrm{kg} /$ day of actual body weight rounded to the nearest $25 \mu \mathrm{g}(20)$. 


\begin{tabular}{|c|c|}
\hline Factor & Considerations \\
\hline Body weight & - The ideal body weight is a better predictor of LT4 dose than the actual body weight (22). \\
\hline Pregnancy status & $\begin{array}{l}\text { - Women being treated for hypothyroidism typically require an increase in their LT4 dose when } \\
\text { pregnant. }\end{array}$ \\
\hline \multirow[t]{2}{*}{$\begin{array}{l}\text { Aetiology of } \\
\text { hypothyroidism }\end{array}$} & $\begin{array}{l}\text { - Patients who have undergone thyroidectomy generally require a higher LT4 dose than patients } \\
\text { with Hashimoto's thyroiditis. }\end{array}$ \\
\hline & $\begin{array}{l}\text { - Patients who have received radioiodine therapy (RAI) for GD may have a variable need for LT4, } \\
\text { depending on the residual functional thyroid tissue. }\end{array}$ \\
\hline Age & $\begin{array}{l}\text { LT4 dose requirement tends to decrease with age despite the decrease in LT4 absorption with } \\
\text { advancing age (23). }\end{array}$ \\
\hline \multirow[t]{2}{*}{$\begin{array}{l}\text { General clinical } \\
\text { context }\end{array}$} & $\begin{array}{l}\text { - Presence of cardiac disease: LT4 therapy may exacerbate angina in patients with ischaemic heart } \\
\text { disease. }\end{array}$ \\
\hline & $\begin{array}{l}\text { - It is recommended to start with a lower dose of LT4 }(12.5-25 \mu \mathrm{g} / \mathrm{day}) \text { with titration in small } \\
\text { increments every } 6 \text { weeks to a full therapeutic dose while paying close attention to the } \\
\text { development of ischaemic symptoms }\end{array}$ \\
\hline $\begin{array}{l}\text { Differentiated } \\
\text { thyroid cancer }\end{array}$ & $\begin{array}{l}\text { - LT4 dose requirement in patients with differentiated thyroid cancer requiring TSH suppression } \\
\text { after thyroidectomy are generally higher and usually between } 2.1-2.7 \mu \mathrm{g} / \mathrm{kg}(24) \text {. }\end{array}$ \\
\hline
\end{tabular}

\subsection{2.. Administration of levothyroxine}

Box 2.2. Administration of levothyroxine

- $\quad$ LT4 should be taken either 60 minutes before breakfast (or in selected patients, at bedtime - 3 or more hours after the evening meal) as co-ingestion of food is likely to impair the absorption

- $\quad$ LT4 intake should be separated from other potentially interfering medications and supplements by 4 hours

- $\quad$ LT4 should be stored at a temperature of less than $25^{\circ} \mathrm{C}$

- Store in the original package in order to protect from light and moisture

\subsubsection{Monitoring of levothyroxine treatment}

Box 2.3. Monitoring of levothyroxine treatment (20)(21)

Monitoring is done with serum TSH level

- Maintain TSH in the normal range (refer the local lab reference values)

- Check TSH in 4-6 weeks after the initiation or dose adjustment of LT4

- $\quad$ Once the TSH level is stable, patients can be monitored yearly

- Dose adjustments should be made when there are large changes in body weight, with ageing, co-treatment with drugs that alter thyroxine metabolism (e.g.: carbamazepine) and with pregnancy

Note: Monitoring is different in central hypothyroidism, peripheral thyroid hormone resistance, and in the presence analytic interference with its measurement. In central hypothyroidism, monitor FT4. 


\subsubsection{Treatment outcome}

Symptomatic improvement is expected within 2 weeks. Optimum treatment with LT4 will also normalize the TSH level (16). Avoid overtreatment, especially in the elderly (20).

\subsubsection{Over-treatment and under-treatment}

All patients should be evaluated for clinical features of over/under treatment. Avoid subnormal serum TSH values, particularly values below $0.1 \mathrm{mIU} / \mathrm{L}$, especially in older persons and postmenopausal women.

\section{Table 2.6. Over and under-treatment with levothyroxine}

\begin{tabular}{lll}
\hline Adverse effects of over treatment & \multicolumn{2}{l}{ Adverse effects of under-treatment } \\
\hline - Increased risk of osteoporosis & $\bullet$ & Dyslipidaemia \\
- Atrial fibrillation (25) & - & Progression of atherosclerotic cardiovascular disease \\
& - & Progression of congestive heart failure \\
& - & Reversible cardiomyopathy \\
\hline
\end{tabular}

\subsection{Management of subclinical hypothyroidism} (SH)

Persistent elevation of TSH with normal FT4 (at least on 2 occasions 3 months apart) is required to establish the diagnosis and consider treatment.

\subsubsection{Consequences of subclinical hypothyroidism}

\section{Progression to overt hypothyroidism $(\mathrm{OH})$}

Annual rate of progression to $\mathrm{OH}$ ranges from 2-4\% (26).

Higher TSH at presentation, presence of TPO antibodies and the underlying disease may predict progression.

Patients who have AITD or received RAI or high-dose therapeutic external radiotherapy are likely to progress to overt hypothyroidism (27).

\section{Cardiovascular disease}

SH may be associated with an increased risk of coronary heart disease (25), heart failure (28), stroke (29), elevated total and LDL cholesterol (30), particularly when the serum TSH concentration is above $10 \mathrm{mU} / \mathrm{L}$.

\section{Non-alcoholic fatty liver disease}

Elevated TSH levels show a positive correlation with the presence of NAFLD (30).

The effects of treating $\mathrm{SH}$ on mortality and reproductive abnormalities are not well studied and available evidence show conflicting results.

\subsubsection{Benefits of TH Replacement in SH}

- Alleviation of hypothyroid signs and symptoms

- May lead to improvements in major adverse cardiovascular events, serum lipids and apolipoprotein concentrations (data limited)

- May improve fertility (data limited)

\subsection{3. $\mathrm{TH}$ replacement in $\mathrm{SH}$}

Dosing considerations are summarized in table 2.7

\section{Table 2.7. Levothyroxine replacement in subclinical hypothyroidism}

\begin{tabular}{ll}
\hline TSH $\geq \mathbf{1 0 ~} \mathbf{m I U} / \mathbf{L}$ & $\begin{array}{l}\text { Considering the high risk of progression to overt hypothyroidism and the increased risk of } \\
\text { cardiovascular disease and its resultant higher mortality, treatment is recommended (21). }\end{array}$ \\
\hline TSH 4.5-10 & $\begin{array}{l}\text { Routine treatment is not recommended. } \\
\text { Treatment is decided by individual factors (e.g.: symptoms of hypothyroidism, positive TPO antibodies, } \\
\text { subfertility or planning for pregnancy) (20). }\end{array}$ \\
\hline
\end{tabular}




\subsubsection{Dosing and monitoring}

Box 2.4. Dosing and monitoring of LT4 treatment in subclinical hypothyroidism

- $\quad$ Start with the lowest dose necessary to normalize the serum TSH concentration, typically 25 to $50 \mu \mathrm{g}$ daily.

- Treatment goal is to normalize serum TSH.

- In patients who do not receive TH replacement, TFT should be repeated at regular intervals.

- In patients with TSH 4.5-10 mIU/L, if symptoms do not improve after starting LT4, re-measure TSH and if the level remains raised, adjust the dose. If symptoms persist while serum TSH is within the reference range, consider stopping LT4

\subsection{Management of hypothyroidism in elderly}

\subsubsection{Physiological changes associated with ageing}

With ageing multiple complex physiological changes occur in HPT axis and peripheral metabolism of TH. Upper limit of normal range for TSH increases progressively with ageing (figure 2.5) (31).

\subsubsection{Guide for decision making}

Diagnosis of overt and subclinical hypothyroidism is made using age specific reference ranges.

Clinical significance of diagnosis and benefits / potential risks of treatment of $\mathrm{SH}$ in elderly are a matter of debate (37) (38) (39).

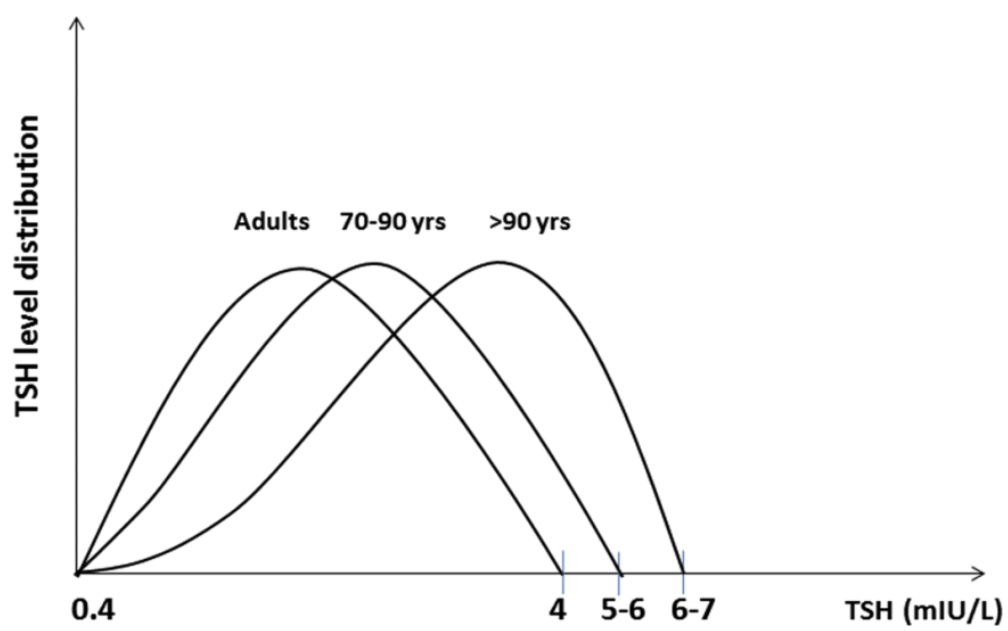

Figure 2.5. Approximate changes in the serum TSH with ageing (31) (Reproduced with permission from Calsolaro V et al. Hypothyroidism in the Elderly: Who Should Be Treated and How? J Endocr Soc. 2019;3(1):146-58).

Treatment with LT4 should be considered in selected patients with higher TSH values or cardiovascular and cognitive dysfunction.

Symptoms attributable to hypothyroidism, frailty, burden of polypharmacy, patient preference and thyroid peroxidase antibody status may be considered in an individual basis to decide on treating $\mathrm{SH}$ (table 2.8) (31).
Use a smaller starting dose $(25 \mu \mathrm{g} /$ day or $0.4-0.5$ $\mu \mathrm{g} / \mathrm{kg} /$ day), since there is a possibility of worsening of subclinical CHD. Dose can be adjusted with clinical and biochemical monitoring (31)(32)(41). 


\section{Table 2.8. Suggested strategy to decide on treating subclinical hypothyroidism in elderly}

\begin{tabular}{|c|c|c|c|c|}
\hline \multirow{2}{*}{$\begin{array}{l}\text { Serum TSH value } \\
(\mathrm{mIU} / \mathrm{L})\end{array}$} & \multicolumn{2}{|c|}{ Fit patient } & \multicolumn{2}{|c|}{ Frail patient } \\
\hline & $65-75$ years & $>75$ years & $65-75$ years & $>75$ years \\
\hline$>10$ & Treat & Treat ${ }^{\mathrm{b}} /$ Observe & Observe/ Treat ${ }^{b}$ & Observe \\
\hline $6-10$ & Observe/ Treat $\mathrm{t}^{\mathrm{b}, \mathrm{c}}$ & Observe/ Treat ${ }^{\mathrm{b}, \mathrm{c}}$ & Observe & Observe \\
\hline $4-6$ & Observe/ Treat ${ }^{\mathrm{b}, \mathrm{c}}$ & Observe & Observe & Observe \\
\hline
\end{tabular}

a- Elevation of serum TSH value should be confirmed by at least a second measurement in 3-6 months

b- Consider treatment in the presence of positive TPO antibodies, symptoms of hypothyroidism, concomitant diseases potentially worsened by mild hypothyroidism (e.g.: heart failure), and patient's wish

c- Consider treatment if serum TSH value rises to $\geq 10 \mathrm{mIU} / \mathrm{L}$

\section{Treatment targets}

Box 2.5. Treatment targets in elderly

In patients between 70-80 years, it is reasonable to keep a TSH target 4-6 mIU/L.

In patients above 80 years even slightly higher TSH reference values may be reasonable.

Iatrogenic subclinical hyperthyroidism should be avoided in these patients since it can be associated with increased cardiac

complications and fractures (33)(34)(35).

\section{Key recommendations: hypothyroidism}

\section{Diagnosis}

Screen for hypothyroidism with TSH and FT4 if clinical features and / or biochemical derangements suggestive of hypothyroidism are present (box 2.1)

Diagnose primary or central hypothyroidism, and overt or subclinical hypothyroidism according to the pattern of TSH and FT4 (figure 2.4).

\section{Treatment: overt hypothyroidism}

Consider age, cardiovascular disease, pregnancy status, cause for hypothyroidism and body weight in determining the starting dose of LT4. Usual starting dose is 1.6 $\mu \mathrm{g} / \mathrm{kg} /$ day (table 2.5).

Advice patients to take levothyroxine in the morning, on empty stomach, and avoid other food or drinks (except water) for 60 minutes. Ensure other drugs interfering with absorption are spaced out (box 2.2).

\section{Treatment: subclinical hypothyroidism}

Consider treatment with LT4 if symptomatic, TSH is $>10$ $\mathrm{mIU} / \mathrm{L}$, has TPO antibodies, has subfertility or is planning for pregnancy (table 2.7).

Start with a low LT4 dose and titrate (box 2.4)

\section{Treatment of elderly}

Consider progressive rise in TSH with ageing in healthy elderly before diagnosing hypothyroidism and deciding on treatment targets in elderly (figure 2.5).

Treat subclinical hypothyroidism in elderly with levothyroxine after considering age, frailty, degree of TSH elevation, TPO antibodies, symptoms and patient's wish (table 2.8).

\section{Follow up}

Reassess TSH in 4-6 weeks after treatment initiation. Aim for clinical euthyroidism and normalization of TSH in primary hypothyroidism and FT4 in central hypothyroidism (box 2.3). Once biochemically stable, reassessment of TSH can be done annually.

\section{Refer to specialist}

Consider referral to a specialist:

- If LT4 dose requirement is unusually high

- Patients with / suspected to have central hypothyroidism or thyroxine resistance

- Hypothyroidism in elderly or with concomitant cardiovascular disease 


\section{THYROTOXICOSIS}

\subsection{Introduction}

Thyrotoxicosis is a clinical state resulting from inappropriately high circulating and tissue $\mathrm{THs}$ irrespective of the origin (36).
Hyperthyroidism is characterized by excessive synthesis and secretion of THs by the thyroid gland.

Thyrotoxicosis can be overt or subclinical depending on the biochemical profile.

\section{Table 3.1. Classification of thyrotoxicosis}

\begin{tabular}{cc}
\hline Overt thyrotoxicosis & Sub-clinical thyrotoxicosis \\
\hline $\begin{array}{c}\text { suppressed or undetectable levels of TSH } \\
\text { increased FT4 and / or FT3 }\end{array}$ & low TSH \\
& normal levels of FT4 and FT3 \\
\hline
\end{tabular}

\subsection{Causes of thyrotoxicosis}

Causes can be broadly classified according to the presence or absence of hyperthyroidism. (Table 3.2)

\section{Table 3.2. Causes of thyrotoxicosis}

\section{Thyrotoxicosis with hyperthyroidism}

Thyrotoxicosis without hyperthyroidism

- Graves disease (GD)

- Toxic multinodular goitre (MNG)

- Toxic adenoma (TA) of thyroid

- TSH secreting pituitary adenoma

- Pituitary resistance to thyroid hormones

- Trophoblastic diseases

- Gestational thyrotoxicosis
- Subacute thyroiditis, painless thyroiditis: Inflammation and release of stores of thyroxine (viruses, drugs or toxins)

- Excess exogenous thyroid hormone - Iatrogenic or factitious

- Exposure to excess iodine

- Ectopic thyroxine source : struma ovarii

- Functional thyroid cancer metastasis

\section{Graves disease}

GD is an autoimmune disorder and is the leading cause of hyperthyroidism (37). About $3 \%$ of women and $0.1 \%$ of men develop GD during their lifetime (38).

TSH receptor antibodies (TRAb) targeted at thyrotropin receptor (TSHR) are central to the pathogenesis of GD (39). Several genes conferring increased susceptibility have been identified and these include genes encoding thyroglobulin, TSHR, HLA-DR $\beta-A r g 74$, the protein tyrosine phosphatase non receptor type 22 (PTPN22), cytotoxic T-lymphocyte-associated antigen 4 (CTLA4), CD25, and CD40 (40).

TRAb is highly sensitive (97\%) and specific (98\%) for the diagnosis of GD. Its presence also predicts extra-thyroid complications of GD and neonatal thyrotoxicosis in the offspring of females planning for pregnancy (38).

Antibodies to thyroglobulin, thyroid peroxidase, sodiumiodide symporter are also present in GD but are not diagnostic.

\section{Sub-acute thyroiditis}

Sub-acute thyroiditis is an inflammatory disease of the thyroid, thought to occur following a viral infection. This is also called de Quervain thyroiditis and subacute granulomatous thyroiditis. It is commoner among young and middle aged females (41). 


\subsection{Clinical features of thyrotoxicosis}

Clinical presentation of thyrotoxicosis depends on the severity, underlying cause and age of onset.

Among elderly, presentation can be atypical, in whom apathy or depression could be the only symptom (42).

\subsubsection{Common clinical presentations of thyrotoxicosis}

Important effects of excess $\mathrm{TH}$ occur within the cardiovascular, neuromuscular and ocular systems (Table 3.3).

\section{Table 3.3. Common clinical presentations of thyrotoxicosis}

\begin{tabular}{|c|c|c|c|}
\hline $\begin{array}{l}\text { Cardiovascular } \\
\text { manifestations }\end{array}$ & $\begin{array}{l}\text { Neuromuscular } \\
\text { manifestations }\end{array}$ & Ocular manifestations & Others \\
\hline $\begin{array}{l}\text { Sinus tachycardia } \\
\text { Systolic hypertension } \\
\text { Atrial flutter } \\
\text { Atrial fibrillation }\end{array}$ & $\begin{array}{l}\text { Hyperactivity and hyper- } \\
\text { reflexia } \\
\text { Anxiety } \\
\text { Tremors } \\
\text { Fatigue } \\
\text { Proximal muscle weakness } \\
\text { Disturbed sleep }\end{array}$ & $\begin{array}{l}\text { Lid lag and lid retraction } \\
\text { Proptosis* } \\
\text { Eye lid swelling* } \\
\text { Conjunctival injection and } \\
\text { chemosis* } \\
\text { Ophthalmoplegia* }\end{array}$ & $\begin{array}{l}\text { Weight loss despite increased } \\
\text { appetite } \\
\text { Warm and moist skin } \\
\text { Menstrual disturbances } \\
\text { Tachypnoea }\end{array}$ \\
\hline
\end{tabular}

* These clinical manifestations are characteristic of Graves orbitopathy (GO).

\subsubsection{Clinical features indicating the aetiology}

Clinical features suggesting a specific aetiology should be identified (Table 3.4).

Table 3.4. Characteristic clinical features favouring an aetiology in patients with thyrotoxicosis

\begin{tabular}{ll}
\hline Aetiology & Characteristic clinical features \\
\hline Graves disease & Usually young female \\
& Diffuse goitre with bruit \\
& Graves orbitopathy \\
& Pretibial myxoedema \\
& Thyroid acropachy \\
Toxic multinodular goitre & Usually older female \\
& Long standing nodular goitre \\
Toxic adenoma & Nodular goitre / solitary nodule \\
Subacute thyroiditis & Following a viral illness / upper respiratory infection \\
& Anterior neck pain: may radiate to throat, ears, jaw and upper chest \\
& Systemic manifestations: fever, malaise, fatigue, myalgia and anorexia \\
& Tender diffuse goitre (37) \\
\hline
\end{tabular}

\subsection{Evaluation of thyrotoxicosis}

\subsubsection{Screening for thyrotoxicosis}

Box 3.1 lists patient categories that should be screened for thyrotoxicosis.

\subsubsection{Diagnosis of thyrotoxicosis}

Serum TSH alone is adequate for screening as it has a high sensitivity for the diagnosis of thyrotoxicosis. A normal TSH rules out thyrotoxicosis.

Serum FT4 level along with serum TSH can be used in initial evaluation, particularly when having to do a second test is inconvenient for the patient. 
Serum TT3 should be done if FT4 is normal and TSH is suppressed, to rule out T3 toxicosis. TT3 assay is more reliable and less variable than FT3 (37). When TT3 is not available, FT3 can be used.

Box 3.1. Indications for screening for thyrotoxicosis

- Patient with clinical features of thyrotoxicosis (see table 3.3)

- Patients with suspected secondary osteoporosis, atrial fibrillation or other tachyarrhythmias

- Patients with thyroid eye signs or features of GO

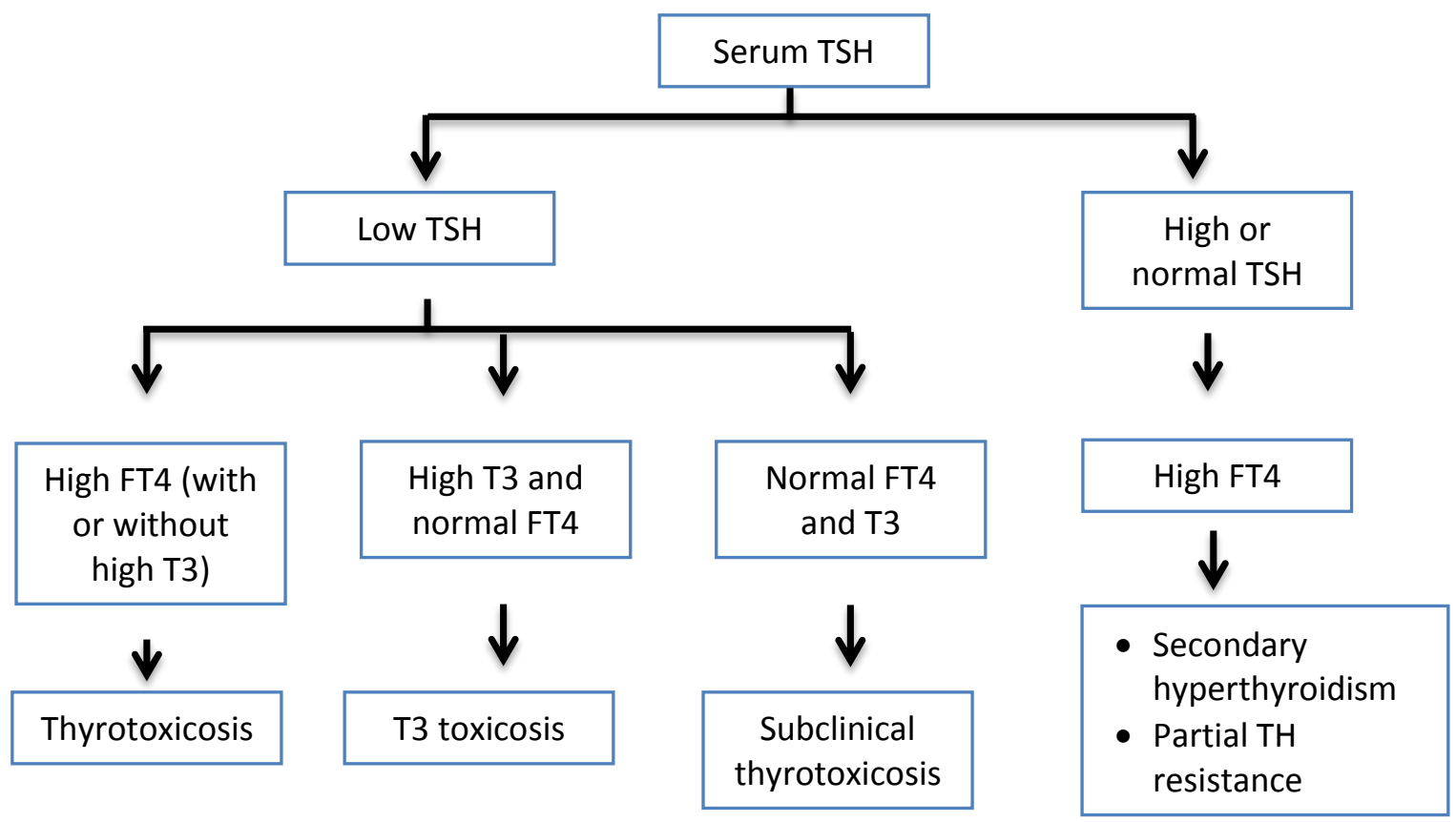

Figure 3.1. Interpretation of thyroid function test in patients with suspected thyrotoxicosis

Note: Acute non-thyroid illnesses can cause a low normal TSH with low normal FT4. TFT should be repeated in few weeks after resolution of the illness.

FT4: free thyroxine, T3: triiodothyronine (free or total)

\subsubsection{Supportive tests for evaluation of} thyrotoxicosis

All patients with thyrotoxicosis (overt or subclinical) should be evaluated for aetiology and complications. 


\begin{tabular}{|c|c|c|c|}
\hline Investigation & Indication & Relevance & Action \\
\hline Full blood count & For all & $\begin{array}{l}\text { Neutropaenia may occur with } \\
\text { thyrotoxicosis } \\
\text { Neutrophil leucocytosis is seen } \\
\text { in subacute thyroiditis }\end{array}$ & $\begin{array}{l}\text { If neutrophil count is }<1000 / \mathrm{mm}^{3} \text {, do not } \\
\text { start ATDs }\end{array}$ \\
\hline $\begin{array}{l}\text { Liver enzymes and } \\
\text { bilirubin }\end{array}$ & For all & $\begin{array}{l}\text { Thyrotoxicosis may cause } \\
\text { cholestasis and transaminitis }\end{array}$ & $\begin{array}{l}\text { If liver enzymes are greater than } 5 \text { times the } \\
\text { ULN, do not start ATDs }\end{array}$ \\
\hline $\begin{array}{l}12 \text { lead ECG with } \\
\text { rhythm strip }\end{array}$ & $\begin{array}{l}\text { For elderly or if } \\
\text { clinically indicated }\end{array}$ & $\begin{array}{l}\text { Tachyarrhythmia } \\
\text { Atrial fibrillation }\end{array}$ & $\begin{array}{l}\text { - Heart rate control with BBs } \\
\text { - Standard management of AF } \\
\text { - If ECG is normal, but has embolic events, } \\
\text { suggest long term ECG monitoring in } \\
\text { liaison with cardiology / cardiac } \\
\text { electrophysiology }\end{array}$ \\
\hline $\begin{array}{l}\text { 2D } \\
\text { echocardiogram }\end{array}$ & $\begin{array}{l}\text { Clinically suspected } \\
\mathrm{HF}\end{array}$ & $\begin{array}{l}\text { - To detect thyrotoxic } \\
\text { cardiomyopathy } \\
\text { - Establish baseline cardiac } \\
\text { function and rule out other } \\
\text { causes for HF }\end{array}$ & $\begin{array}{l}\text { Correction of thyrotoxicosis and symptomatic } \\
\text { management of } \mathrm{HF} \text { in liaison with cardiology }\end{array}$ \\
\hline DXA scan & $\begin{array}{l}\text { For adults > } 65 \\
\text { years / with other } \\
\text { risk factors for } \\
\text { osteoporosis }\end{array}$ & $\begin{array}{l}\text { Thyrotoxicosis is a cause for } \\
\text { low BMD }\end{array}$ & $\begin{array}{l}\text { - Treatment of thyrotoxicosis } \\
\text { - Optimize calcium and vitamin D intake } \\
\text { - Consider anti-resorptives * }\end{array}$ \\
\hline
\end{tabular}

AF: Atrial fibrillation, ATD: Anti thyroid drugs, BBs: beta blockers, BMD: Bone mineral density, DXA: dual-energy X-ray absorptiometry, ECG: electrocardiogram, HF: heart failure, ULN: upper limit of normal

*according to osteoporosis guidelines

Suggested pathway for evaluation of thyrotoxicosis is summarized in figure 3.2.

\subsection{Management of thyrotoxicosis}

Treatment of thyrotoxicosis is aimed at:

1. Symptom relief

2. Specific treatment

3. Treatment of complications

\subsubsection{Symptom relief}

Symptoms of thyrotoxicosis are treated with beta blockers (BB), irrespective of the aetiology, aiming to maintain heart rate less than 90 beats per minute. When BBs are contraindicated, non-dihydropyridine calcium channel blockers (CCB) can be used (Table 3.6). Once FT4 is normalized, BBs / CCBs can be discontinued.

\subsubsection{Specific treatment}

Anti-thyroid drugs (ATD), radioactive iodine therapy (RAI) or thyroidectomy are options for treatment of hyperthyroidism. Table 3.7 summarizes a comparison of these modalities. 


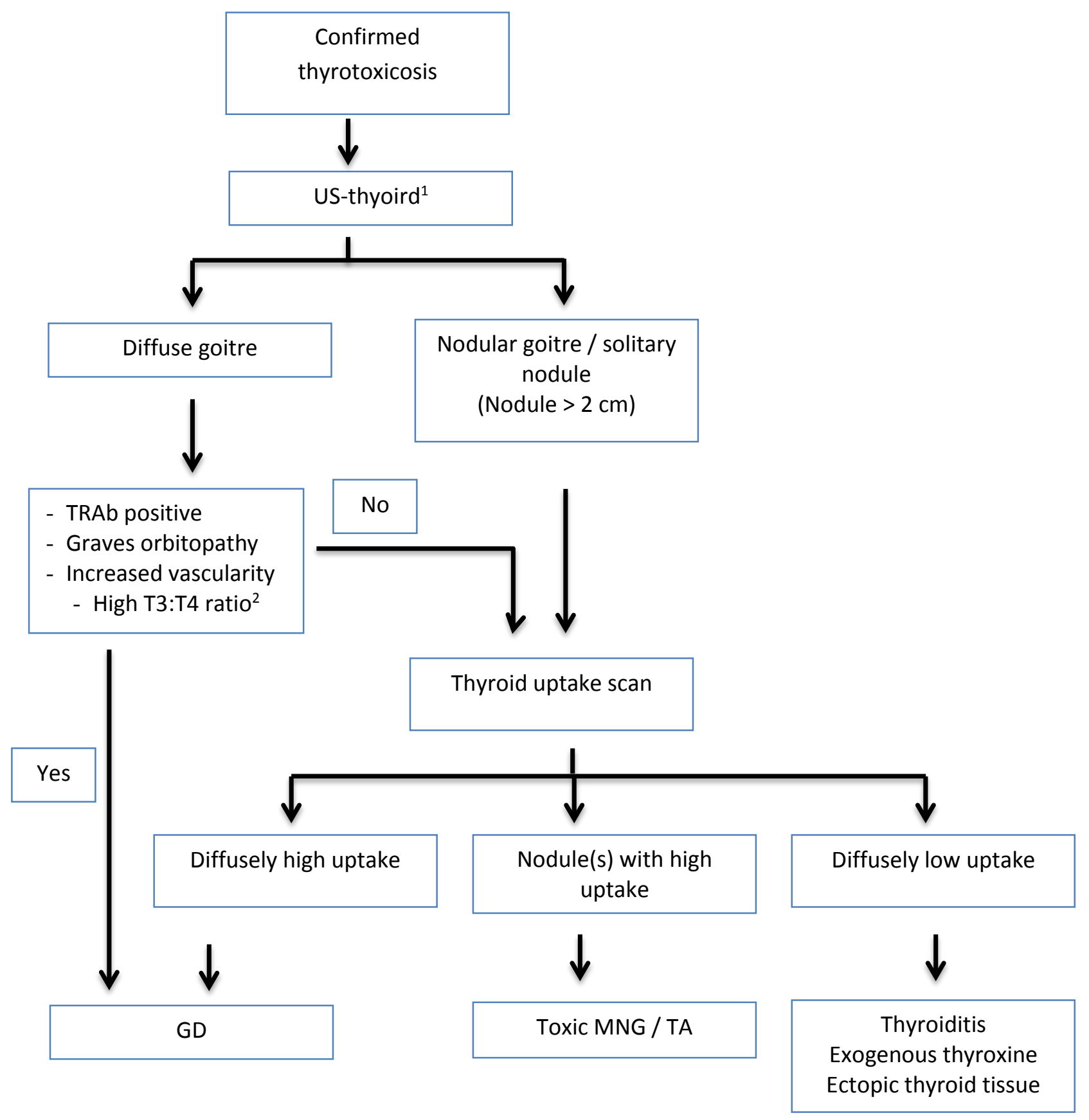

Figure 3.2. Evaluation for aetiology in a patient with thyrotoxicosis

${ }^{1}$ Presence of thyroid eye signs in a patient with thyrotoxicosis and diffuse goitre on examination confirms the diagnosis of Graves disease and ultrasound is not essential in such patients

All clinically nodular goitres should be evaluated with an ultrasound to determine the risk of malignancy.

2 TT3:TT4 ratio $>20 \mathrm{ng} / \mathrm{mcg}$ or FT3:FT4 ratio $>30 \mathrm{pg} / \mathrm{ng}$ suggests GD (43). FT3:FT4 ratio > $30 \mathrm{pg} / \mathrm{ng}$ is $87.0 \%$ sensitive and $62.5 \%$ specific to differentiate GD from thyroiditis (44).

GD: Graves disease, MNG: multinodular goitre, TA: Toxic adenoma, TRAb: TSH receptor antibodies, US: ultrasound 


\begin{tabular}{|c|c|c|c|}
\hline Agent & Dose & Frequency & Remarks \\
\hline Propranolol & $10-40 \mathrm{mg}$ & $2-3$ times a day & Non-selective $\beta$ antagonist \\
\hline Atenolol & $25-100 \mathrm{mg}$ & $1-2$ times a day & $\begin{array}{l}\text { Relatively } \beta \text {-1 selective antagonist } \\
\text { Avoid in pregnancy }\end{array}$ \\
\hline Metoprolol & $25-50 \mathrm{mg}$ & $2-3$ time a day & $\begin{array}{l}\text { Relatively } \beta-1 \text { selective antagonist } \\
\text { Extended release preparations can be given } 1-2 \text { times a day }\end{array}$ \\
\hline Verapamil & $80-160 \mathrm{mg}$ & 3-4 times a day & Maximum dose $480 \mathrm{mg}$ per day \\
\hline Diltiazem & $30-120 \mathrm{mg}$ & 3-4 times a day & Maximum dose $480 \mathrm{mg}$ per day \\
\hline
\end{tabular}

Adapted from American Thyroid Association guidelines for the management of thyrotoxicosis 2016 (37).

\section{Table 3.7. Specific treatment options available for management of hyperthyroidism}

\begin{tabular}{|c|c|c|c|}
\hline & Anti-thyroid drugs & Radio-active iodine & Thyroidectomy \\
\hline Advantages & $\begin{array}{l}\text { Rapid control within weeks to } \\
\text { months }\end{array}$ & $\begin{array}{l}\text { Definitive cure of thyrotoxicosis } \\
\text { in most with minimum adverse } \\
\text { effects }\end{array}$ & $\begin{array}{l}\text { Definitive cure of thyrotoxicosis } \\
\text { with immediate disease control }\end{array}$ \\
\hline Disadvantages & $\begin{array}{l}\text { - Risk of recurrence / need } \\
\text { for lifelong therapy with } \\
\text { toxic nodules } \\
\text { - Drug side effects }\end{array}$ & $\begin{array}{l}\text { - Need for lifelong LT4 } \\
\text { - Risks of radiation (should } \\
\text { avoid pregnancy for 6-12 } \\
\text { months. Men should avoid } \\
\text { fathering for 3-4 months) } \\
\text { - Several months to establish } \\
\text { control } \\
\text { - May worsen GO }\end{array}$ & $\begin{array}{l}\text { - Surgical complications } \\
\text { - Risk of recurrent laryngeal } \\
\text { nerve palsy } \\
\text { - Risk of hypoparathyroidism } \\
\text { - Needs lifelong LT4 }\end{array}$ \\
\hline $\begin{array}{l}\text { Compelling } \\
\text { indications }\end{array}$ & $\begin{array}{l}\text { - Need for rapid control } \\
\text { - Pregnant } \\
\text { - Unfit for surgery } \\
\text { - Institutionalized / unable to } \\
\text { follow post RAI precautions } \\
\text { - Limited life expectancy } \\
\text { - Moderate to severe GO } \\
\text { - Mild disease, small goitre, } \\
\text { negative or low TRAb titre }\end{array}$ & $\begin{array}{l}\text { - Unfit for surgery } \\
\text { - ATD intolerance / contra- } \\
\text { indicated / failure } \\
\text { - Periodic paralysis } \\
\text { - Heart failure } \\
\text { - Pulmonary hypertension } \\
\text { - GD with low chance of } \\
\text { remission }\end{array}$ & $\begin{array}{l}\text { - Planning pregnancy within } 6 \text { - } \\
12 \text { months } \\
\text { - Moderate to severe active GO } \\
\text { - Suspicion of cancer* } \\
\text { - Large goitre > } 80 \mathrm{~g} \\
\text { - Compression symptoms } \\
\text { - Hyperparathyroidism needing } \\
\text { surgery } \\
\text { - Retrosternal goitre }\end{array}$ \\
\hline Contra-indications & $\begin{array}{l}\text { - Major adverse events with } \\
\text { ATDs in the past }\end{array}$ & $\begin{array}{l}\text { - Pregnancy / planning for } \\
\text { pregnancy within } 6 \text { months } \\
\text { - Lactation } \\
\text { - Inability to comply with } \\
\text { safety precautions } \\
\text { - Suspected thyroid cancer } \\
\text { - Moderate to severe active } \\
\text { GO } \\
\text { - Retrosternal goitre }\end{array}$ & $\begin{array}{l}\text { - Unfit for surgery } \\
\text { - Pregnancy - relative } \\
\text { contraindication. Can do in } \\
\text { 2nd trimester, still increased } \\
\text { risk of preterm delivery, } \\
\text { recurrent laryngeal nerve palsy } \\
\text { and hypoparathyroidism } \\
\text { - Lack of access to high volume } \\
\text { surgeon }\end{array}$ \\
\hline
\end{tabular}

$*$ Nodule $>4 \mathrm{~cm}$, nodule with relatively low uptake, cytology suspicious or indeterminate

ATD: anti-thyroid drugs, GD: Graves disease, GO: Graves orbitopathy, RAI: radio-active iodine, TRAb: TSH receptor antibodies 


\section{Anti-thyroid drugs - Thionamides}

ATDs are the preferred first line agent for hyperthyroidism of any aetiology. A guide for starting dose is given in table 3.8 .

\section{Adverse effects of thionamides}

Most adverse effects of thionamides occur within 3-12 weeks of treatment initiation. Table 3.9 summarizes their characteristics and management.

\begin{tabular}{ll}
\multicolumn{2}{c}{ Table 3.8. Starting dose of carbimazole } \\
\hline Free T4 level & Carbimazole (mg/day)* \\
\hline $1-1.5 \times \mathrm{ULN}$ & $10-15$ \\
$1.5-2 \times \mathrm{ULN}$ & $15-30$ \\
$2-3 \times \mathrm{ULN}$ & $45-60$ \\
\hline
\end{tabular}

ULN: Upper limit of normal

* When higher doses are required, administration in divided doses may help faster normalization of FT4.

Table 3.9. Adverse effects of thionamide anti-thyroid drugs

\begin{tabular}{ll}
\hline \multicolumn{1}{c}{ Adverse effect } & \multicolumn{1}{c}{ Description } \\
\hline $\begin{array}{l}\text { Skin rash } \\
(3-6 \%)\end{array}$ & $\begin{array}{l}\text { Maculo-papular. } \\
\text { Pruritic in some }\end{array}$ \\
& \\
Agranulocytosis & Absolute neutrophil count $<500$ \\
$(0.11-0.27 \%)$ & $\mathrm{mm}^{3}$ \\
& Dose dependent and reversible
\end{tabular}

Hepatotoxicity $(0.1$ $-4.0 \%$

Teratogenicity
Carbimazole / methimazole causes cholestasis.

PTU causes hepatitis.

\begin{abstract}
3-4\% with carbimazole (more severe: tracheo-oesophageal fistula, choanal atresia, aplasia cutis) \& 2-3\% with PTU (milder: pre-auricular sinus, renal tract anomalies)
\end{abstract}

- Minor reaction - continue ATD, brief course of antihistamine

- Major reactions - stop ATD, offer alternative treatment

- Stop ATD

- Screen for and treat sepsis with broad spectrum antibiotics

- Consider G-CSF and glucocorticoids

- Avoid thionamides for life (45). Offer alternative treatment*

- Neutrophil 1000 - $1500 / \mathrm{mm}^{3}$ : may continue ATD with close monitoring of neutrophil counts

- If liver enzymes are $>3$ times the ULN or show a progressive rising trend, temporarily discontinue ATD and monitor LFT at least once a week.

- Treat thyrotoxicosis with non-thionamide ATD or other definitive treatment strategy.

- When liver enzymes return to normal, alternative thionamide ATD can be considered, unless the liver injury was severe.

- Use PTU up to 16 weeks. Switch back to carbimazole thereafter (to avoid PTU associated liver injury)

\footnotetext{
ATD: anti-thyroid drugs, G-CSF: granulocyte colony stimulating factor, PTU: propylthiouracil, RAI: radio-active iodine, ULN: upper limit of normal, LFT: liver function test *alternative treatment: non-thionamide ATDs / RAI / surgery

All patients commenced on ATD should have baseline full blood count, liver enzymes and bilirubin levels measured.
} 
Routine monitoring of these investigations are not beneficial since side effects are abrupt in onset, almost always symptomatic and affect only a minority of patients.

Patients should be provided written advice to stop ATD and report urgently if any of the following develops while on ATDs:

- Sore throat, fever, other symptoms of an infection

- Jaundice, pale stools, pruritus, abdominal pain, vomiting, anorexia

- $\quad$ Skin rash

\section{Non-thionamide ATDs}

Non-thionamide ATDs can be used in following situations:

1. Maximum tolerated thionamide dose fails to achieve euthyroidism

2. Thionamides are contraindicated due to severe adverse effects

Box 3.2. Patient preparation for RAI (46),(37),(47)
3. Need for rapid reversal of thyrotoxicosis - thyrotoxic storm, pre-operative setting

In these circumstances, patients should be referred to a specialist to consider non-thionamide therapies.

\section{Radioactive iodine therapy (RAI)}

RAI offers a non-invasive definitive therapy by ablating the hyperfunctioning thyroid tissue.

It is administered as a single oral capsule containing radioactive iodine-131 isotope which concentrates in the hyperfunctioning thyroid gland.

If the gland is diffusely hyperfunctioning (as in GD), the entire gland will take up iodine. In toxic MNG, often the rest of the gland is hypo-functioning and therefore, most of the dose will accumulate in the hyper-functioning nodule and rest of the gland will be relatively preserved.

Patient preparation for RAI is shown in box 3.2.

Expected outcomes are summarized in table 3.10 .

Follow up plan is outlined in box 3.3.

Informed written consent. Emphasize the need to

$\checkmark$ avoid pregnancy for 6-12 months / fathering for 3-4 months.

$\checkmark \quad$ stop lactation for 6-12 weeks before RAI and not to recommence until next pregnancy (55)

$\checkmark$ avoid close contact with children and pregnant mothers for several days after therapy (specific recommendation should be according to radio-oncology protocols)

$\checkmark \quad$ some may need long term thyroxine

Exclude pregnancy - Negative pregnancy test within 72 hours before receiving RAI irrespective of contraceptive use (55).

Minimize risk of thyrotoxic crisis after RAI

$\checkmark \quad$ Try to achieve euthyroidism

$\checkmark$ Give BBs irrespective of thyroid status, unless contraindicated (46).

$\checkmark$ ATDs can be used to reduce the risk, but will also reduce the efficacy of RAI (56).

Discontinue thionamide ATDs

$\checkmark$ This is to allow iodine trapping in thyroid follicular cells

$\checkmark$ Stop carbimazole 5-7 days and propylthiouracil 2-3 days prior to RAI

$\checkmark \quad$ Those can be resumed 3-7 days after RAI, especially in patients who are at risk of worsening thyrotoxicosis (46).

$\checkmark \quad$ Lithium carbonate can be continued during RAI as it may improve the outcome by prolonging the iodine trapping within thyroid tissue.

Optimize other medical co-morbidities 
Table 3.10. Outcomes of radioiodine therapy according to the aetiology of thyrotoxicosis $(48)(49)(50)(51)(37)(52)(45)$

\begin{tabular}{lll}
\hline Aetiology & Resolution of thyrotoxicosis & Development of hypothyroidism \\
\hline Graves disease & $70-90 \%$ by 1 year & In $40 \%$ by 8 weeks and $80 \%$ by 16 weeks \\
Toxic adenoma & $93.7 \%$ (overall) & In $28 \%$ by 5 years \\
Toxic multinodular goitre & $81.1 \%$ (overall) & In $4 \%$ by 5 years \\
\hline
\end{tabular}

Box 3.3. Follow up investigations after RAI for hyperthyroidism

1 Repeat TFTs 1-2 months after RAI and 4-6 weekly thereafter until stabilized

2 Once hypothyroidism develops, thyroxine replacement therapy should be commenced.

3 If thyrotoxicosis persists beyond 6 months, a repeat dose of RAI should be considered.

\section{Adverse effects of RAI}

- Thyroiditis (often mild and transient)

- Worsening of GO

- Sialadenitis, mucositis, dry eyes / excessive tearing, dry mouth, altered taste sensation

Some studies have raised concerns about an association between solid organ malignancy related mortality and RAI, but, this remain inconclusive due to methodological limitations (53)(54). Therefore, no recommendations are made for routine screening for cancer among RAI recipients, beyond the recommendations for general population.

\section{Thyroidectomy}

Thyroidectomy helps to rapidly achieve cure of hyperthyroidism.

Potential complications of thyroidectomy are listed in box 3.4

Patients with hyperthyroidism undergoing thyroidectomy should be optimized as described in table 3.12 .

Box 3.4. Complications of thyroidectomy*

\begin{tabular}{|c|l|}
\hline 1 & Permanent hypothyroidism requiring lifelong thyroxine replacement in all \\
\hline 2 & Damage to recurrent laryngeal nerve causing hoarseness of voice (less than $5.8 \%)(55)(56)$ \\
\hline 3 & Damage to parathyroid gland causing hypoparathyroidism, often transient but rarely permanent $(1.9 \%)(57)$ \\
\hline 4 & Complications related to surgery (haematoma, permanent scar) and general anaesthesia \\
\hline
\end{tabular}

*In high volume centres, surgical complications are rare. However, these considerations should be discussed with the patient before surgery. Following thyroidectomy, replacement doses of levothyroxine can be commenced from first postoperative day. Consider delaying levothyroxine if pre-operative control of thyrotoxicosis was poor.

Table 3.12. Preparation for thyroidectomy

\begin{tabular}{|c|c|c|}
\hline 1 & Written informed consent & $\begin{array}{l}\text { - Discuss potential complications (box 3.4) including need for lifelong } \\
\text { thyroxine after surgery }\end{array}$ \\
\hline 2 & $\begin{array}{l}\text { Achieve euthyroid/ near-euthyroid } \\
\text { state }\end{array}$ & $\begin{array}{l}\text { - To minimize the incidence and severity of peri-operative thyrotoxic crisis } \\
\text { - ATDs can be discontinued after the morning doses on the day of surgery }\end{array}$ \\
\hline 3 & $\begin{array}{l}\text { Check and correct calcium and vitamin } \\
\text { D level }\end{array}$ & $\begin{array}{l}\text { - To minimize risk and severity of post-operative hypocalcaemia and hungry } \\
\text { bone syndrome }\end{array}$ \\
\hline 4 & Pre-operative Lugol's iodine & $\begin{array}{l}\text { - Helps to control hyperthyroidism as well as reduce vascularity of the thyroid } \\
\text { gland }\end{array}$ \\
\hline & \multicolumn{2}{|c|}{ Seek specialist opinion when patients undergo surgery before achieving good biochemical control of thyrotoxicosis } \\
\hline
\end{tabular}




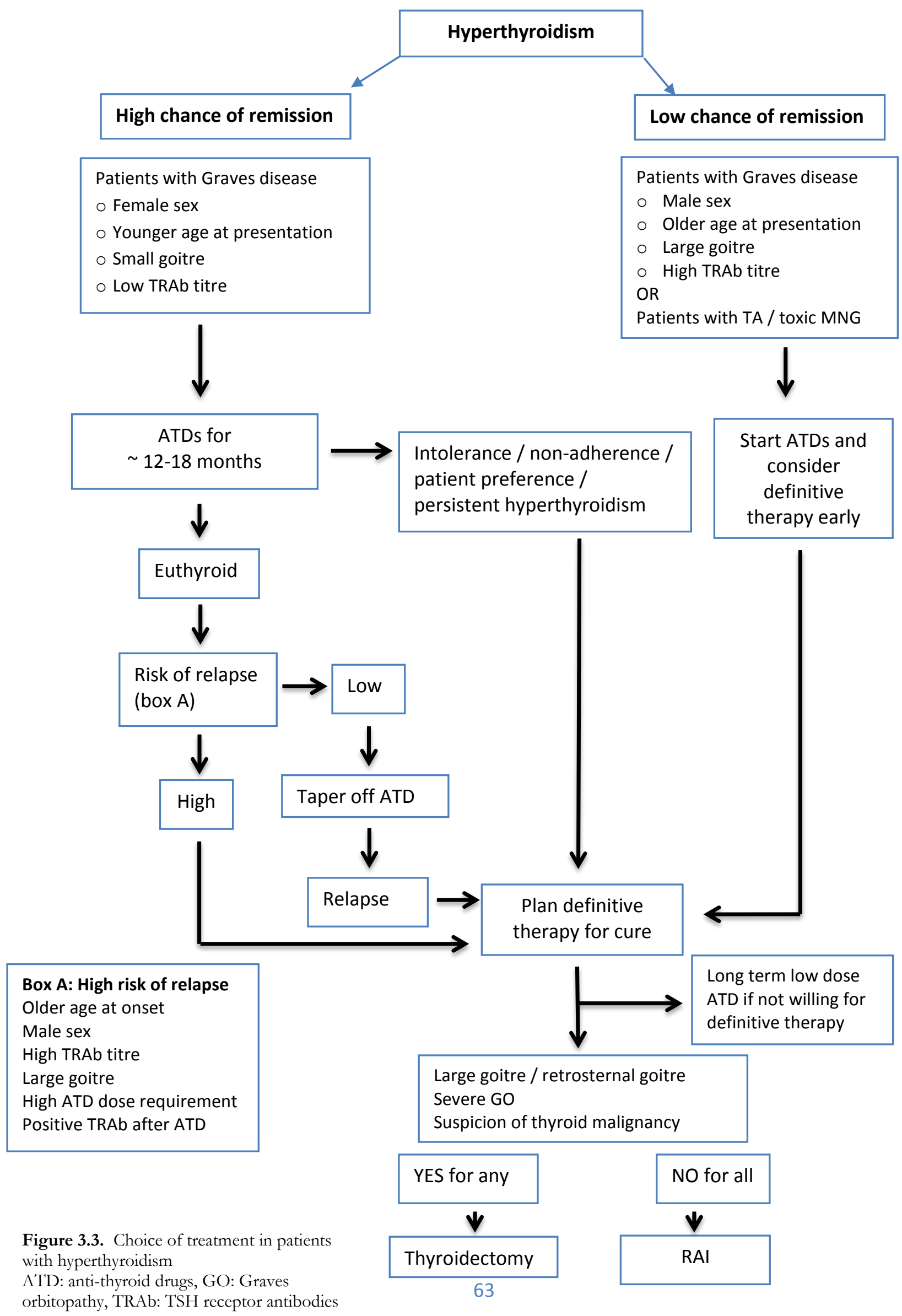




\subsection{Graves orbitopathy}

\subsubsection{Epidemiology}

The incidence of Graves orbitopathy (GO) is 42.2 per million per year (20.1\% of the incidence of GD) (58). The incidence of moderate to severe and very severe GO is 16.1 per million per year in the general population, with a female: male ratio of 5:1 and peak incidence between 40 and 60 years $(59)(60)$.

\subsubsection{Pathophysiology}

TRAbs (from plasma cells) and cytokines (from T cells) activate retro-ocular fibroblasts and adipocyte which bear TSH receptors (61).

Fibroblasts secrete glycosaminoglycans (GAG) such as hyaluronic acid (62)(63). Hydrophilic GAGs cause fluid accumulation, muscle swelling, increased pressure within the orbit and impaired venous drainage. These changes, together with retro-ocular adipogenesis, displace the eyeball forward and cause extra-ocular muscle dysfunction.

Box 3.5 Clinical Activity Score (CAS) for assessment of disease activity of GO

\begin{tabular}{|l|}
\hline Spontaneous retrobulbar pain \\
\hline Pain on attempted upward or downward gaze \\
\hline Redness of eyelids \\
\hline Redness of conjunctiva \\
\hline Swelling of caruncle or plica \\
\hline Swelling of eyelids \\
\hline Swelling of conjunctiva (chemosis) \\
\hline Add 1 mark for each positive feature. Inactive GO $=$ CAS $<\mathbf{3}$, Active GO $=$ CAS $\geq \mathbf{3}$ \\
\hline
\end{tabular}

Impact of GO on the individual's quality of life (QoL) and psychosocial well-being should be assessed.

\section{Assessment of quality of life}

\subsubsection{Evaluation of $\mathrm{GO}$}

Selecting the most appropriate treatment for individual patients depends on the activity and severity of the eye changes.

\section{Assessment of disease activity}

Disease activity can be assessed using Clinical Activity Score (CAS) (box 3.5). A CAS $\geq 3 / 7$ is indicative of active GO (64).

\section{Assessment of disease severity}

Disease severity can be measured according to EUGOGO classification (Table 3.13).

Severity is rated as mild, moderate to severe and sight threatening (or very severe).

Visual acuity, colour vision, corneal and retinal assessment should be performed to recognize sight threatening GO.

Consider orbital imaging (MRI or CT with contrast) when diagnosis is doubted or for surgical planning.
The use of GOQoL questionnaire, a disease-specific and validated tool, is recommended in routine clinical practice (65). 


\begin{tabular}{|c|c|c|}
\hline Disease severity & Description & Features \\
\hline Mild GO & $\begin{array}{l}\text { GO has only a minor impact on daily life, } \\
\text { insufficient to justify immunosuppressive } \\
\text { or surgical treatment. }\end{array}$ & $\begin{array}{l}\text { One or more of the following: } \\
\text { - minor lid retraction }(<2 \mathrm{~mm}) \\
\text { - } \text { mild soft-tissue involvement } \\
\text { - } \text { exophthalmos }<3 \mathrm{~mm} \text { above normal for race and } \\
\text { - gender } \\
\text { - } \text { no or intermittent diplopia } \\
\text { corneal exposure responsive to lubricants }\end{array}$ \\
\hline $\begin{array}{l}\text { Moderate-to- } \\
\text { severe GO }\end{array}$ & $\begin{array}{l}\text { Non-sight-threatening GO with eye disease } \\
\text { causing sufficient impact on daily life to } \\
\text { justify the risks of immunosuppression (if } \\
\text { active) or surgical intervention (if inactive). }\end{array}$ & $\begin{array}{l}\text { Two or more of the following: } \\
\text { - lid retraction } \geq 2 \mathrm{~mm} \\
\text { - } \text { moderate or severe soft-tissue involvement } \\
\text { - } \text { exophthalmos } \geq 3 \mathrm{~mm} \text { above normal for race and } \\
\text { gender } \\
\text { - inconstant or constant diplopia }\end{array}$ \\
\hline $\begin{array}{l}\text { Sight-threatening } \\
\text { GO (very severe } \\
\text { GO) }\end{array}$ & Likely to lose vision if not treated urgently & $\begin{array}{l}\text { Dysthyroid optic neuropathy (DON) and / or corneal } \\
\text { breakdown }\end{array}$ \\
\hline
\end{tabular}

\subsection{4. . Management of GO}

\section{General measures in management of GO}

\section{Refer for specialized management}

Patients with GO should be referred to a specialized centre providing endocrinology and ophthalmology expertise, except for the mildest forms that improve with normalizing thyroid status and local lubricants (65).
Elevation of head-end while sleeping and diuretics can help to relieve periorbital oedema

\begin{tabular}{|c|c|c|}
\hline Action & Description & Recommendation \\
\hline Stop smoking & $\begin{array}{l}\text { Smoking increases the severity (66)(67), risk of progression } \\
\text { and de novo occurrence of GO after RAI therapy (68) and } \\
\text { delays or mitigates the benefits of immunosuppressive } \\
\text { treatment for GO (69). } \\
\text { Smoking cessation improves outcome of GO (70). }\end{array}$ & $\begin{array}{l}\text { All patients with Graves disease should } \\
\text { be advised to stop smoking. Arrange for } \\
\text { support if needed. }\end{array}$ \\
\hline $\begin{array}{l}\text { Restore euthyroid } \\
\text { state }\end{array}$ & $\begin{array}{l}\text { Hypo and hyperthyroid states worsen GO. } \\
\text { ATD and surgery do not have a significant effect (68). } \\
\text { RAI may worsen GO (71) (72) }\end{array}$ & $\begin{array}{l}\text { Offer steroid prophylaxis before RAI } \\
\text { for patients at risk for deterioration of } \\
\text { GO (table 3.15) }\end{array}$ \\
\hline Topical therapy & $\begin{array}{l}\text { increased palpebral fissure width, exophthalmos, slow blink } \\
\text { rate, lid lag, lagophthalmos and poor Bell's phenomenon } \\
\text { predisposes to dry eyes and corneal damage }\end{array}$ & $\begin{array}{l}\text { Topical artificial tears to prevent drying } \\
\text { (65) }\end{array}$ \\
\hline
\end{tabular}

. RAI therapy can worsen GO. Risk can be reduced by administration of glucocorticoids, starting 1-3 days after RAI (table 3.15). Avoid RAI in patients with active moderate to severe or sight threatening GO.

\section{Specific management}

Specific management of GO will depend on the disease activity and the severity as described in figure 3.4. 
In addition to supportive measures, specific treatment options for GO of different severity categories are summarized in table 3.17. Seek specialist advice before administration of immunosuppressive therapies.

\section{Table 3.15. Steroid prophylaxis with RAI treatment in patients with GO}

\begin{tabular}{|l|l|l|}
\hline Risk category & \multicolumn{1}{|c|}{ Description } & \multicolumn{1}{c|}{ Glucocorticoid use } \\
\hline Very low & $\begin{array}{l}\text { No GO } \\
\text { Inactive GO, euthyroid and non- } \\
\text { smoking }\end{array}$ & Not necessary \\
\hline Low & $\begin{array}{l}\text { Active mild GO. No risk factors for } \\
\text { deterioration }\end{array}$ & $\begin{array}{l}\text { Oral prednisolone } 0.2 \mathrm{mg} / \mathrm{kg} \text { body weight per day for } 6 \text { weeks } \\
\text { and tail off over } 1-2 \mathrm{months}(73)\end{array}$ \\
\hline High & $\begin{array}{l}\text { Active mild GO, with risk factors for } \\
\text { deterioration }\end{array}$ & $\begin{array}{l}\text { Oral prednisone } 0.3-0.5 \mathrm{mg} / \mathrm{kg} \text { body weight } / \text { daily for } 1 \mathrm{month} \\
\text { and tail off over } 2-3 \mathrm{months}\end{array}$ \\
\hline
\end{tabular}

Risk factors for GO deterioration are smoking and high TRAb titres.

Consider risks of glucocorticoids including deterioration of diabetes control, risk of infections, osteoporosis and psychiatric illnesses patients with active moderate to severe GO or sight threatening GO.

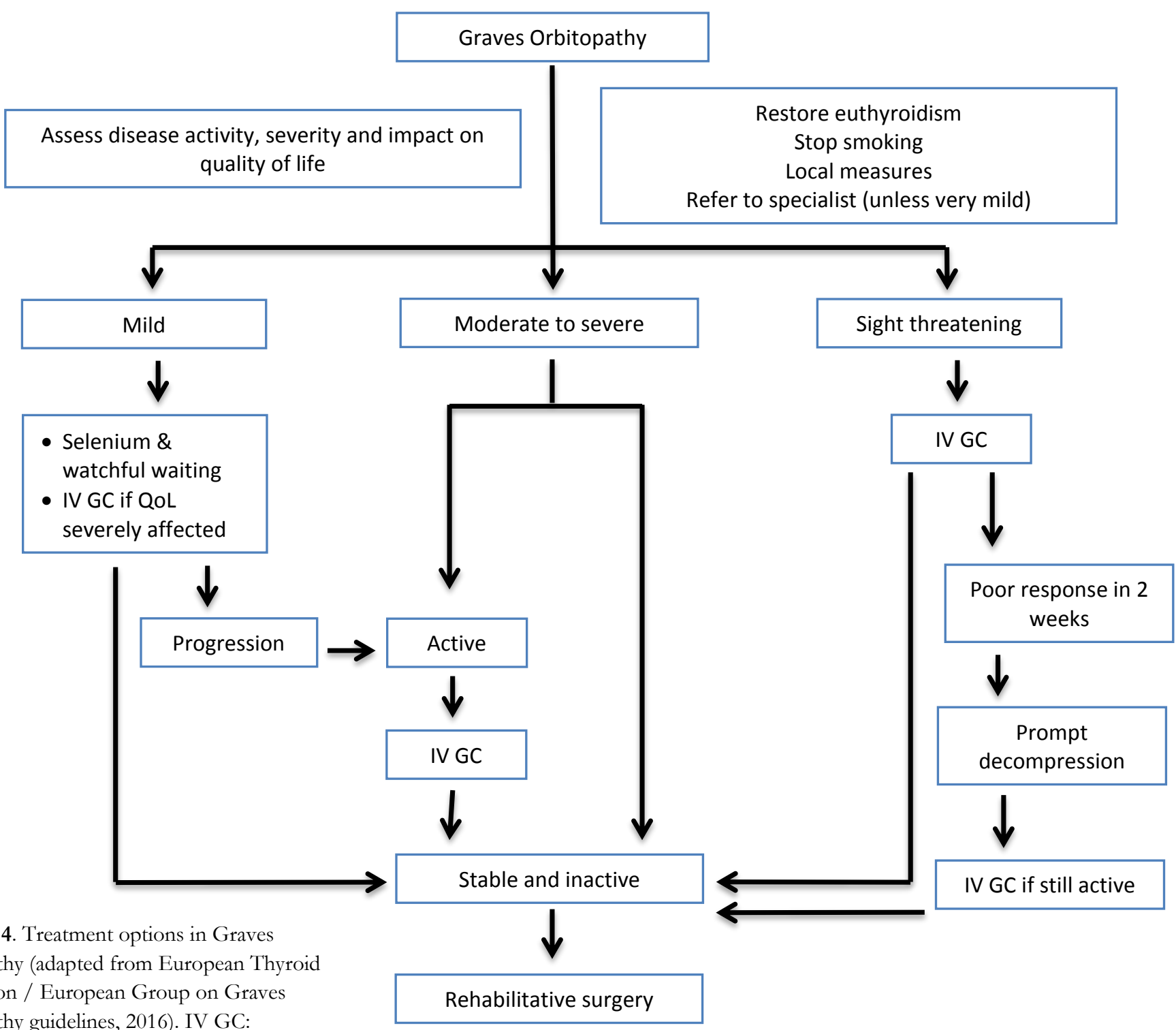

Figure 3.4. Treatment options in Graves Orbitopathy (adapted from European Thyroid Association / European Group on Graves Orbitopathy guidelines, 2016). IV GC: intravenous glucocorticoids 


\section{Table 3.16. Specific management of GO according to severity and activity}

\begin{tabular}{|c|c|c|}
\hline Severity & Treatment & Remarks \\
\hline Mild GO & $\begin{array}{l}\text { - Sodium selenite } 100 \mu \mathrm{g} \text { twice a day for } 6 \text { months } \\
\text { - Consider immunosuppressive therapy for active } \\
\text { disease and orbital surgery for inactive disease }\end{array}$ & $\begin{array}{l}\text { Selenium improves eye manifestations, QoL and } \\
\text { prevents GO progression to severe stages }(74) .\end{array}$ \\
\hline $\begin{array}{l}\text { Active moderate } \\
\text { to severe GO }\end{array}$ & $\begin{array}{l}\text { - IV methyl prednisolone (MP) } 0.5 \mathrm{~g} \text { weekly for } 6 \\
\text { weeks and } 0.25 \mathrm{~g} \text { weekly for } 6 \text { weeks ( } 4.5 \mathrm{~g} \text { in } \\
\text { total) }(75)(76)(77) \text {. } \\
\text { - Consider } 2 \text { nd line options for partial / no } \\
\text { response and for recurrences (table } 3.17) \text {. }\end{array}$ & $\begin{array}{l}\text { - Cumulative dose of IV MPs should not } \\
\text { exceed } 8.0 \mathrm{~g} \\
\text { - } \\
\text { Avoid IV MP in patients with recent viral } \\
\text { hepatitis, significant hepatic dysfunction, } \\
\text { severe cardiovascular morbidity or psychiatric } \\
\text { disorders } \\
\text { - Control diabetes and hypertension before IV } \\
\text { MP }\end{array}$ \\
\hline $\begin{array}{l}\text { Sight } \\
\text { threatening GO }\end{array}$ & $\begin{array}{l}\text { - IV MP } 0.5-1 \mathrm{~g} \text { for } 3 \text { consecutive days or on } \\
\text { alternate days during the } 1 \text { st week. } \\
\text { - Can be repeated after a week ( } 78)(79) \text {. } \\
\text { - Surgical orbital decompression within } 2 \text { weeks if } \\
\text { response is poor. }\end{array}$ & Treat as an emergency to prevent blindness \\
\hline $\begin{array}{l}\text { Inactive } \\
\text { moderate to } \\
\text { severe GO }\end{array}$ & $\begin{array}{l}\text { - Elective rehabilitative surgery after } 6 \text { months of } \\
\text { disease inactivity, when visual functions and / or } \\
\text { QoL is affected }\end{array}$ & Refer to a centre with expertise for orbital surgery \\
\hline
\end{tabular}

Table 3.17. Second line treatment of moderate-severe and active GO

\begin{tabular}{|c|c|}
\hline $\begin{array}{c}\text { Second line } \\
\text { therapy }\end{array}$ & Remarks \\
\hline IV GCs & If the patient tolerates and cumulative dose of MP does not exceed $8 \mathrm{~g}$. \\
\hline Mycophenolate & $250 \mathrm{mg}$ oral twice a day for 6 months $(80)$ \\
\hline \multicolumn{2}{|l|}{ Mofetil } \\
\hline Orbital radiotherapy & $\begin{array}{l}\text { As effective as oral GCs, potentiates the effect of oral GCs and improves diplopia and eye muscle } \\
\text { motility (81)(82). }\end{array}$ \\
\hline Cyclosporine & $5-7.5 \mathrm{mg} / \mathrm{kg}$ for up to one year (83). \\
\hline Rituximab & $\begin{array}{l}\text { Can be used as a second line treatment(84), especially in patients with a relatively short disease } \\
\text { duration(85). } \\
1000 \mathrm{mg} \text { IV two doses two weeks apart. }\end{array}$ \\
\hline Tocilizumab & IV tocilizumab $8 \mathrm{mg} / \mathrm{kg} 4$ weekly for 16 weeks \\
\hline \multirow[t]{3}{*}{ Teprotumumab } & Human monoclonal antibody inhibitor of the insulin-like growth factor-1 (IGF-1) receptor \\
\hline & This is the first therapy to be reported to reduce proptosis in GO (86). \\
\hline & Administered every three weeks as an IV infusion (10 mg/ kg initial dose, then $20 \mathrm{mg} / \mathrm{kg}$ ) \\
\hline
\end{tabular}

GC: Glucocorticoids, MP: methyl prednisolone

\subsubsection{Treatment of other extra-thyroid} manifestations of GD

Therapy with topical steroids applied under an occlusive plastic dressing for 3-10 weeks has been helpful for pretibial myxoedema. In severe cases, pulse glucocorticoid therapy may be tried. No therapy has been proven to be effective for thyroid acropachy.

\subsection{Evaluation and management of subacute thyroiditis}

\subsubsection{Natural course of the disease}

Thyrotoxic features are seen in about 50\% (transient and resolves in about 2-8 weeks)

This will be followed by a hypothyroid phase lasting for about 2-8 weeks. Minority will develop permanent hypothyroidism (87)(88). 


\subsubsection{Evaluation of sub-acute thyroiditis}

Useful investigations and expected results are summarized in table 3.18 .

In some patients with predominant thyrotoxic features differentiation from Graves disease would be difficult.
Following would guide the differentiation in clinical practice (Table 3.19).

Table 3.18. Summary of evaluation of sub-acute thyroiditis

\begin{tabular}{ll}
\hline Test & Result \\
\hline TFT & Initially elevated FT4 and FT3 with low TSH \\
& Later TFT may show overt or subclinical hypothyroidism followed by \\
& normalization \\
Inflammatory markers & Elevated ESR, CRP. Neutrophil leucocytosis \\
Thyroxine binding globulin & Elevated \\
Anti-thyroid antibodies & Negative in many \\
Ultrasound thyroid & Mildly enlarged gland with hypoechogenicity and normal flow in \\
& colour Doppler $(62)$ \\
Radio-iodine or technetium uptake scan & Reduced uptake $(62)(87)$ \\
\hline
\end{tabular}

Table 3.19. Features differentiating subacute thyroiditis from Graves disease

\begin{tabular}{lll}
\hline & Sub-acute thyroiditis & Graves disease \\
\hline Thyroid hormones & Markedly elevated free T4 compared to & Greater rise of free T3 \\
& free T3 & (FT3/FT4 $>30 \mathrm{pg} / \mathrm{ng})$ \\
& (FT3/FT4 $<30 \mathrm{pg} / \mathrm{ng})$ & \\
Laboratory parameters & Elevated ESR, CRP, White cell count & Not usually seen \\
& and mild anaemia & \\
TRAb & Negative & Positive \\
Colour Doppler & Reduced blood flow & Increased blood flow \\
Radio-iodine or technetium uptake & Reduced & Increased \\
\hline
\end{tabular}

\subsubsection{Management of sub-acute thyroiditis}

\section{Table 3.20. Summary of the management of sub-acute thyroiditis}

\begin{tabular}{|c|c|c|}
\hline Monitor disease & \multicolumn{2}{|c|}{ Monitor thyroid functions to detect disease evolution over time } \\
\hline \multirow{3}{*}{$\begin{array}{l}\text { Treat features of } \\
\text { local / systemic } \\
\text { inflammation }\end{array}$} & Minimal symptoms & May be managed conservatively \\
\hline & $\begin{array}{l}\text { Mild neck pain and mild } \\
\text { systemic symptoms }\end{array}$ & $\begin{array}{l}\text { High dose NSAIDs (e.g. Ibuprofen } 1200-3200 \mathrm{mg} / \text { day in divided } \\
\text { doses) }\end{array}$ \\
\hline & $\begin{array}{l}\text { severe symptoms or poor } \\
\text { response to NSAIDs } \\
\text { within 2-3 days }\end{array}$ & $\begin{array}{l}\text { Oral steroid therapy } \\
\text { - Prednisolone } 40 \mathrm{mg} / \text { day and tapered slowly within } 2-8 \text { weeks or } \\
\text { - Prednisolone } 15 \mathrm{mg} / \text { day to taper within } 6 \text { weeks and increase } \\
\text { only if inadequately responding (89). }\end{array}$ \\
\hline \multirow[t]{2}{*}{$\begin{array}{l}\text { Treat thyroid } \\
\text { dysfunction }\end{array}$} & $\begin{array}{l}\text { Symptoms of } \\
\text { hyperthyroidism }\end{array}$ & $\begin{array}{l}\text { - Non-selective BBs / CCBs } \\
\text { - No place for ATDs or RAI }\end{array}$ \\
\hline & During hypothyroid phase & Treat with LT4 \\
\hline
\end{tabular}




\section{Key recommendations - Thyrotoxicosis and Graves orbitopathy}

Diagnosis

Perform TSH in patients with clinical features of thyrotoxicosis, premature unexplained osteoporosis, tachyarrhythmias or suspected Graves orbitopathy. If suppressed, perform free T4 and where necessary total T3 / free T3 (figure 3.1). All patients with thyrotoxicosis should have full blood count, liver enzymes and bilirubin levels tested. Consider ECG, 2D echo and DXA scan where appropriate (table 3.5). Assess clinically and consider ultrasound scan of thyroid, TSH receptor antibodies and thyroid uptake scan to establish the aetiology (figure 3.2).

\section{Treatment of thyrotoxicosis}

Treat symptoms of thyrotoxicosis with beta blockers or calcium channel blockers (table 3.6).

Use anti-thyroid drugs for control of hyperthyroidism. Consider definitive therapy with radioiodine or thyroidectomy early where appropriate (table 3.7 and figure 3.3).

Determine starting dose of ATDs according to the FT4 level at presentation (table 3.8).

Advice patients (preferably in writing) regarding neutropaenia, hepatotoxicity and skin rash (table 3.9).

De Quervain thyroiditis - Offer symptomatic therapy for thyrotoxicosis and NSAIDs or short course of glucocorticoids for neck pain and / or systemic inflammatory symptoms. Periodically monitor TFT to recognize progression to hypothyroidism.

\section{Follow up - thyrotoxicosis}

Monitor response to ATDs by clinical assessment and FT4 levels.

\section{Management of Graves orbitopathy}

Assess activity, severity, vision (acuity, colour vision) and quality of life (section 3.6.3)

Consider ultrasound neck, TRAb and MRI orbits for diagnosis and planning treatment
Active GO should be treated with systemic glucocorticoids. Consider second line therapies for more severe disease or if response is poor (section 3.6.4).

\section{Refer to specialist}

In patients with thyrotoxicosis, refer to a specialist if

- Diagnosis / aetiology of thyrotoxicosis is uncertain

- Control is inadequate with ATDs

- Intolerant of ATDs

- Planning for RAI or thyroidectomy

In patients with Graves orbitopathy,

- All patients except the mildest cases should be referred for specialized care

- Refer to ophthalmologist for visual assessment and / or surgery (urgent decompression for sight threatening GO or elective rehabilitative surgery) 


\subsection{THYROID DYSFUNCTION AND PREGNANCY}

\subsection{Introduction}

Increased demand for TH during the pregnancy is met by the compensatory mechanisms of HPT axis in the presence of adequate thyroid reserve (90)(91). Important physiological alterations of the thyroid gland and its functions are illustrated in the figure 4.1.

\subsection{Interpretation of TFT during pregnancy}

Changes in TFTs during normal pregnancy are summarized in table 4.1

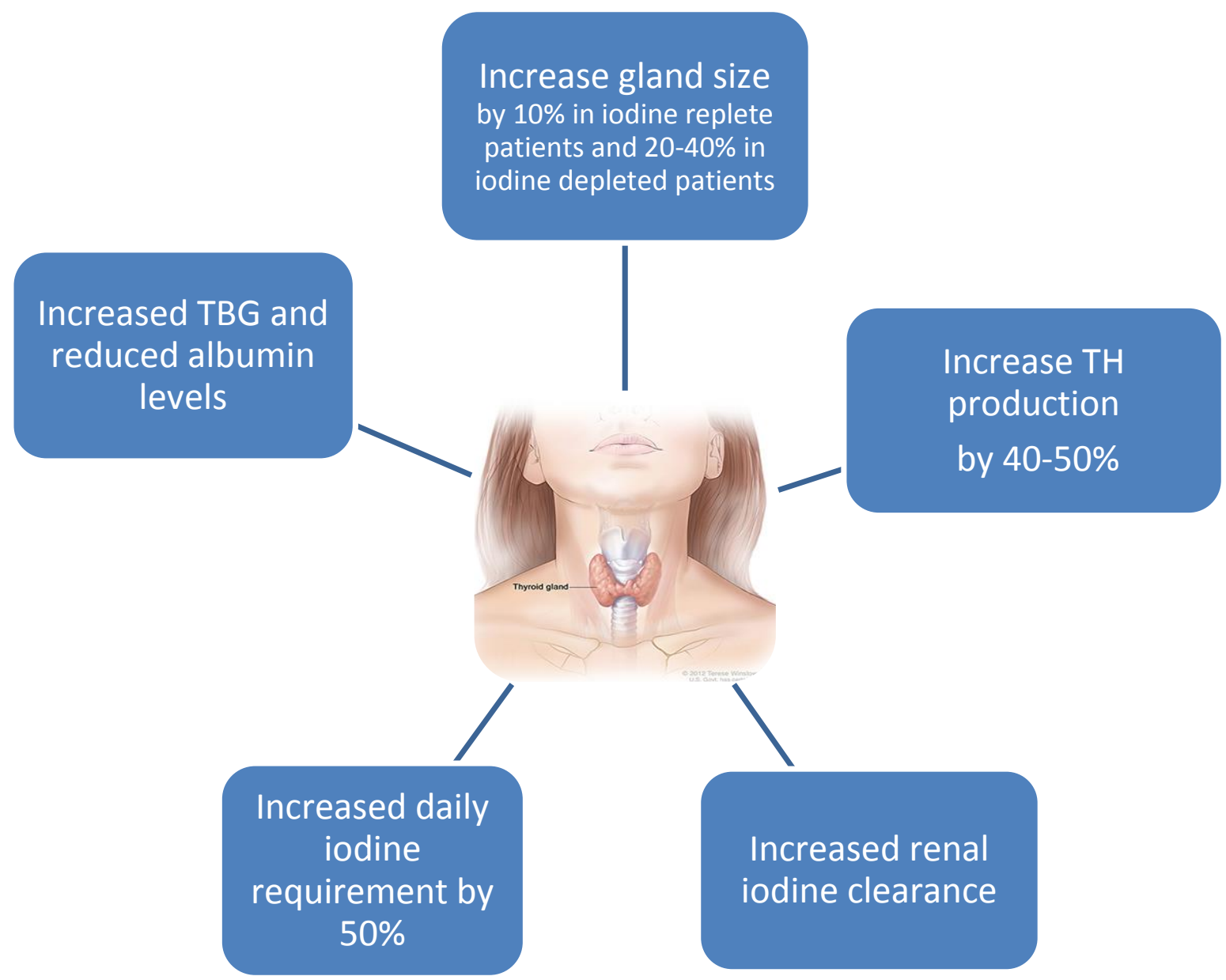

Figure 4.1. Pregnancy associated alterations in thyroid physiology

TBG: thyroid binding globulin, TH: thyroid hormone

\subsection{Hypothyroidism in pregnancy}

Impaired or inadequate adaption to the increased physiological demand due to pathological conditions causes hypothyroidism leading to adverse maternal and foetal consequences 


\begin{tabular}{|c|c|}
\hline Physiological alteration & Interpretation \\
\hline $\begin{array}{l}\text { Increased serum hCG levels in the } 1 \text { st trimester (peak in } \\
\text { the } 10 \text { th week of pregnancy) }\end{array}$ & $\begin{array}{l}\text { - hCG stimulates TSHR due to structural homology with TSH } \\
\text { molecule } \\
\text { - Elevated TH levels and suppressed TSH levels during 1st } \\
\text { trimester }\end{array}$ \\
\hline Elevation of TBG and reduction of serum albumin levels & $\begin{array}{l}\text { - } \\
\text { Elevated TT4 and TT3 } \\
\text { - TT4 is } 1.5 \text { times higher than non-pregnant reference range } \\
\text { - FT4 assay is highly variable and should use population } \\
\text { specific reference range if available }\end{array}$ \\
\hline $\begin{array}{l}\text { Lowered reference range of the TSH levels due to } \\
\text { multiple factors } \\
\text { - Ethnicity } \\
\text { - Genetics } \\
\text { - Geography } \\
\text { - TPO antibody status } \\
\text { - Iodine status } \\
\text { - TSH assay use }\end{array}$ & $\begin{array}{l}\text { Following trimester specific reference ranges are recommended } \\
\text { according to available local and regional data } \\
\text { - 1st Trimester : } 0.1-2.5 \mathrm{mIU} / \mathrm{L} \\
\text { - 2nd Trimester: } 0.1-3.0 \mathrm{mIU} / \mathrm{L} \\
\text { - 3rd Trimester: } 0.1-3.0 \mathrm{mIU} / \mathrm{L}\end{array}$ \\
\hline
\end{tabular}

hCG: human chorionic gonadotrophin

\section{Table 4.2. Adverse foetal and maternal consequences of hypothyroidism in pregnancy}

\begin{tabular}{lll}
\hline & Overt hypothyroidism & $\begin{array}{l}\text { Subclinical hypothyroidism and isolated } \\
\text { hypothyroxinaemia of pregnancy }\end{array}$ \\
\hline - Foetal & • Miscarriages & - Preterm birth, miscarriages \\
& - Premature birth & - TPO antibody positivity further increases the risk \\
& - Low birth weight & - LT4 replacement has not shown any benefit of reducing the \\
& - Impaired neurocognitive development & risk $(92)(95)(96)(97)$ \\
- Maternal & Gestational hypertension $(90)(91)$ & Pre-eclampsia, placental abruption \\
\hline
\end{tabular}

\subsubsection{Evaluation}

\section{Screening}

Universal screening cannot be recommended due to unavailability of strong evidence of benefit and dynamicity of TFT throughout the pregnancy. Screening is recommended in high risk groups [section 2.5, box 2.1](90)(91) .

\section{Diagnosis}

Hypothyroidism in pregnancy is considered to be a disease spectrum (Table 4.3).

\section{Table 4.3. Diagnosis of hypothyroidism in pregnancy}

\begin{tabular}{ll}
\hline Overt hypothyroidism & Elevated TSH* and a decreased FT4 \\
Subclinical hypothyroidism & Elevated TSH* levels with normal FT4 \\
Isolated hypothyroxinaemia & Normal TSH level with low FT4
\end{tabular}

*Above the upper limit of trimester specific reference range 


\subsubsection{Management}

\section{Overt hypothyroidism}

Table 4.4. summarises management of overt hypothyroidism in pregnancy.

\section{Subclinical hypothyroidism}

Due to conflicting evidence on benefit, treatment of $\mathrm{SH}$ is recommended to be individualized. Algorithm in figure 4.2 gives a guide to treatment (Figure 4.2).

\section{Table 4.4. Management of overt hypothyroidism in pregnancy(90)(98)(99)}

\begin{tabular}{cl}
\hline Hypothyroidism diagnosed during pregnancy \\
\hline - & Start LT4 $2.33 \mu \mathrm{g} / \mathrm{kg} / \mathrm{day}$ \\
\hline Hypothyroidism diagnosed before pregnancy \\
\hline Patients on full replacement dose require $40-50 \%$ dose increment \\
- In patients with autoimmune hypothyroidism, $25 \%$ increment may be adequate \\
- Increase the dose as soon as pregnancy is suspected (1st missed period) \\
- Doubling the dose on weekend days is sufficient to achieve a $30 \%$ dose increment
\end{tabular}

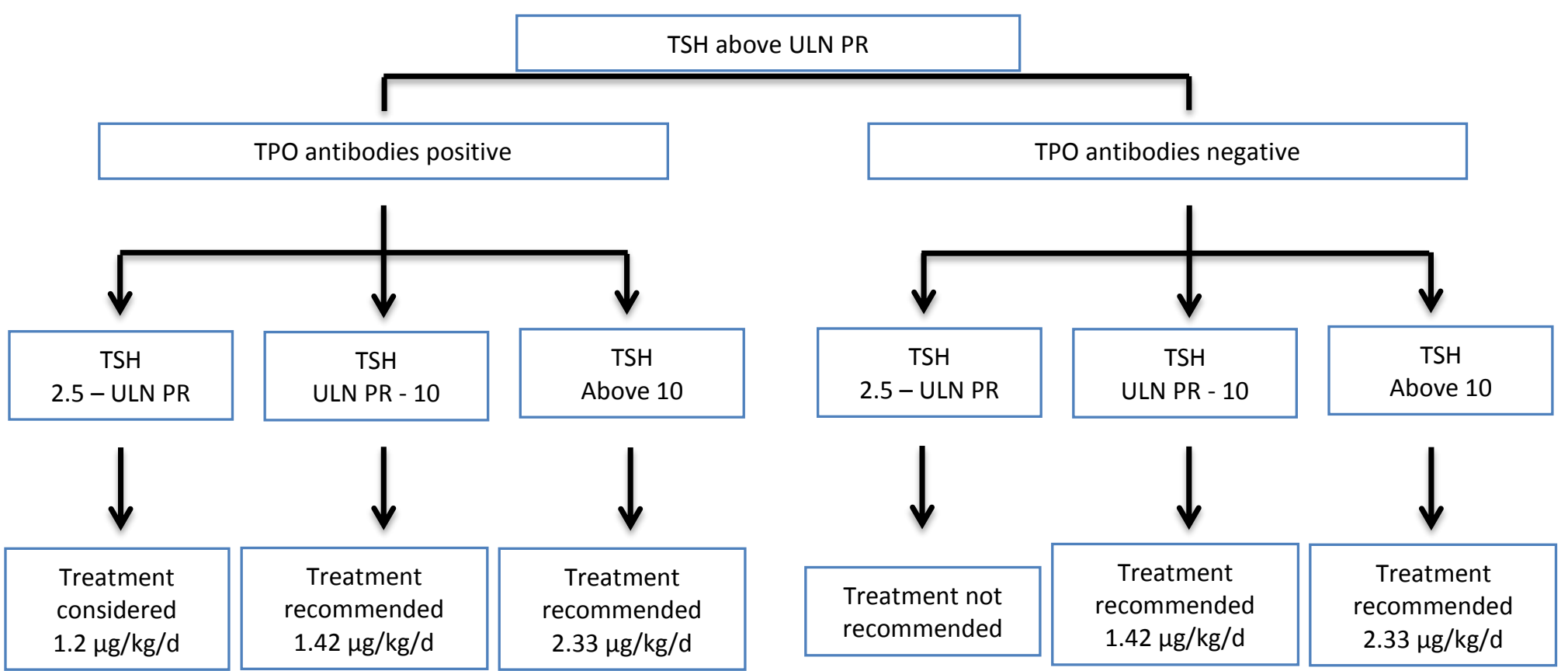

Figure 4.2. Treatment algorithm for subclinical hypothyroidism in pregnancy (90)(98)(95)

* If TPO antibody testing is not available consider treatment with LT4 if TSH is between 2.5 - 4 mIU/L and should start treatment if TSH is above $4 \mathrm{mIU} / \mathrm{L}$. ULN PR: upper limit of normal for pregnancy specific reference range

\section{Isolated hypothyroxinaemia}

LT4 therapy is not recommended routinely due to unavailability of evidence of benefit(90)(92). Adequacy of iodine intake should be ensured (100).

\subsubsection{Follow up and monitoring}

\section{Goal of treatment}

Maintaining TSH level within lower half of trimester specific reference range or $<2.5 \mathrm{mIU} / \mathrm{L}$ is recommended (90) 


\section{Monitoring}

Measure serum TSH approximately every 4 weeks until mid-gestation and at least once near 30 weeks of gestation (90)

\subsubsection{Management of hypothyroidism during post- partum period}

Consider following factors:

- LT4 requirement decreases to pre-pregnancy level after delivery (101).
- Subclinical hypothyroidism in pregnancy is usually transient (102).

- Some may develop exacerbation of autoimmunity, causing transient thyrotoxicosis due to post-partum thyroiditis (103)(104).

- $\quad$ Positive TPO antibodies predict risk of persistent hypothyroidism (105).

Table 4.5 describes a guide in managing patients with hypothyroidism during post-partum period.

TFTs should be rechecked at around six weeks postpartum and treatment adjusted accordingly.

\section{Table 4.5. Management of hypothyroidism during post-partum period}

\begin{tabular}{|l|l|}
\hline Overt hypothyroidism & Return to pre-pregnancy dose provided the patient was euthyroid with that dose \\
\hline Diagnosed before pregnancy & Two thirds of the dose in third trimester \\
\hline Diagnosed during pregnancy & Continue at half of the third trimester dose (101)(106) \\
\hline Subclinical hypothyroidism & Stop treatment, follow up with TFT \\
\hline $\begin{array}{l}\text { Lower TSH, negative TPO Ab, low LT4 } \\
\text { dose requirement during pregnancy }(\leq \\
25 \mu g / \text { day) }\end{array}$ & \\
\hline
\end{tabular}

\subsection{Hypothyroidism and thyroid-autoimmunity in fertility management}

\section{Table 4.6. Hypothyroidism and thyroid autoimmunity in fertility management}

\begin{tabular}{|c|c|c|c|}
\hline Thyroid disorder & Fertility issue & Impact & Intervention \\
\hline \multirow{3}{*}{$\begin{array}{l}\text { Overt } \\
\text { hypothyroidism }\end{array}$} & Subfertility & Impairs fertility (90) & Treatment with LT4 to achieve \\
\hline & & & euthyroidism \\
\hline & Undergoing ART & Impairs ART success & $\begin{array}{l}\text { Treatment with LT4 to achieve } \\
\text { euthyroidism }\end{array}$ \\
\hline \multirow[t]{2}{*}{$\begin{array}{l}\text { Subclinical } \\
\text { hypothyroidism }\end{array}$} & Subfertility & $\begin{array}{l}\text { No clear evidence on effect and benefit of } \\
\text { treatment }\end{array}$ & $\begin{array}{l}\text { Consider low dose LT4 since TH } \\
\text { rise may be inadequate in pregnancy } \\
(90)\end{array}$ \\
\hline & Undergoing ART & $\begin{array}{l}\text { Treatment may be beneficial when TSH }>4 \\
\mathrm{mIU} / \mathrm{L}\end{array}$ & Consider low dose LT4 therapy \\
\hline $\begin{array}{l}\text { Thyroid } \\
\text { autoimmunity } \\
\text { (positive thyroid }\end{array}$ & Subfertility & $\begin{array}{l}\text { There is no clear evidence on association } \\
\text { between fertility and thyroid autoimmunity } \\
\text { or benefit of treatment }(107)(108)\end{array}$ & No recommendations on treatment \\
\hline $\begin{array}{l}\text { antibodies) with } \\
\text { euthyroidism }\end{array}$ & Undergoing ART & $\begin{array}{l}\text { Most of the high quality studies do not show } \\
\text { benefit of treating these patients. }\end{array}$ & Treatment not recommended \\
\hline
\end{tabular}

ART: Assisted reproductive technology 
During ovarian hyperstimulation for ART there would be alteration in TFT due to several reasons including increased thyroid binding globulins and increased hCG. Therefore, it is recommended to perform thyroid function tests either before or 1-2 weeks after ovarian hyperstimulation.

\subsection{Hyperthyroidism in pregnancy}

\subsubsection{Causes of hyperthyroidism in pregnancy}

Gestational thyrotoxicosis and GD are the two most common aetiologies. A guide for clinical differentiation and management are summarized in table 4.7.

Table 4.7. Comparison of gestational thyrotoxicosis and Graves disease

\begin{tabular}{|c|c|c|}
\hline & Gestational thyrotoxicosis & Graves disease (GD) \\
\hline \multirow[t]{2}{*}{$\begin{array}{l}\text { Clinical } \\
\text { presentation }\end{array}$} & $\begin{array}{l}\text { - Occurs in } 1-3 \% \text { of pregnancies } \\
\text { - } \quad \text { typically in the first half of gestation } \\
\text { - Associated with hyperemesis gravidarum, } \\
\text { hydatidiform mole, multiple gestation, } \\
\text { choriocarcinoma } \\
\text { - } \quad \text { Less severe than GD }\end{array}$ & $\begin{array}{l}\text { - May present with a diffuse goitre and } \\
\quad / \text { or eye signs }\end{array}$ \\
\hline & \multicolumn{2}{|c|}{$\begin{array}{l}\text { - Tachycardia, heat intolerance and excessive sweating: could mimic the non-specific } \\
\text { symptoms of pregnancy itself } \\
\text { - Loss of weight despite intact appetite, anxiety, and tremors may be seen in both the } \\
\text { conditions. }\end{array}$} \\
\hline \multirow[t]{2}{*}{ Investigations } & \multicolumn{2}{|c|}{$\begin{array}{l}\text { Serum TSH suppressed }(<0.1 \mathrm{mU} / \mathrm{L}) \text { or undetectable }(<0.01 \mathrm{mU} / \mathrm{L}) \text { and a FT4 \& / or FT3 (or } \\
\text { TT4 \& / or TT3) exceeds the pregnancy specific normal range }\end{array}$} \\
\hline & Serum T4 disproportionately elevated than T3 & $\begin{array}{ll}\text { - } & \text { Serum T3 disproportionately } \\
& \text { elevated than T4 } \\
\text { - } & \text { TRAb positive }\end{array}$ \\
\hline Management & $\begin{array}{ll}\text { - } & \text { Hydration } \\
\text { - } & \text { Antiemetics for vomiting } \\
\text { - } & \text { BBs such as metoprolol, propranolol (10- } \\
& 40 \mathrm{mg} / 6-8 \text { hourly) usually for 2-6 weeks } \\
\text { - } & \text { ATDs not recommended }\end{array}$ & - $\quad$ Refer section 4.5.2. \\
\hline Prognosis & $\begin{array}{l}\text { Serum FT4 normalizes by } 14-18 \text { th week of } \\
\text { gestation }\end{array}$ & $\begin{array}{l}\text { Improves in latter part of gestation due to a } \\
\text { reduction of TRAb levels and rarely, due to } \\
\text { the change in activity of TRAb from } \\
\text { stimulatory to inhibitory. }\end{array}$ \\
\hline
\end{tabular}

ATD: anti-thyroid drugs, BB: beta blockers, TRAb: TSH receptor antibodies

\subsubsection{Management of Graves disease in pregnancy}

\section{Pregnancy planning}

Poor disease control increases the risk of miscarriages, pregnancy induced hypertension, intrauterine growth restriction, preterm labour and maternal congestive cardiac failure.
Practice contraception until stably euthyroid (biochemically euthyroid at least twice, 1 month apart) (37).

\section{Preconception adjustment of treatment}

These considerations are summarized in table 4.8 


\begin{tabular}{ll}
\hline Scenario & Option(s) \\
\hline $\begin{array}{l}\text { Treated with ATD for 12-18 months, } \\
\text { euthyroid with small ATD dose } \\
\text { (carbimazole 5-10 mg/day), TRAb }\end{array}$ & $\begin{array}{l}\text { Stop ATD, monitor TFT 1-2 weekly in first trimester and 2-4 weekly } \\
\text { thereafter (90). } \\
\text { negative }\end{array}$ \\
\hline On high doses of ATD & $\begin{array}{l}\text { Consider RAI / surgery (discuss the need to delay pregnancy) } \\
\text { Continue ATD: switch from carbimazole to propylthiouracil } \\
\text { Young women, regular cycles: switch when planning for conception }\end{array}$ \\
& Older women / irregular cycles : switch when pregnancy is diagnosed \\
\hline
\end{tabular}

\section{Treatment during pregnancy}

\section{Treatment goals}

- TSH: pregnancy specific reference range

- FT4: at or just above trimester specific reference range

- TT4: 1.5 times above the reference range for non-pregnant females

\section{Adjusting therapy}

PTU is associated with maternal hepatitis / fulminant liver necrosis / liver failure. Therefore switch back to carbimazole after 16 weeks, after which risk of teratogenicity is minimal (109).

\section{Adverse effects}

Teratogenicity (see section 3.5.2, table 3.9)

BB beyond 6 weeks of gestation may increase the risk of foetal growth restriction (110)

\section{Other treatment options}

RAI is absolutely contraindicated in pregnant women due to the possible risk of miscarriages, foetal thyroid ablation and birth defects.

Thyroidectomy may be considered in patients who develop allergy or agranulocytosis with antithyroid agents and preferably done during the second trimester

\section{Foetal monitoring}

All foetuses of women with GD should be monitored for signs of thyrotoxicosis with foetal heart rate and growth rate (111).
TRAb is a useful predictive marker of foetal hyperthyroidism.

Women with GD and high TRAb levels, even if euthyroid, warrant monitoring for foetal and neonatal hyperthyroidism.

\subsection{Thyrotoxicosis during post-partum period}

\subsubsection{Post-partum thyroiditis}

Commonly seen within a year from delivery and the prevalence is around $5 \%(1.1-16.7 \%)(112)$.

It is characterized by the occurrence of either transient thyrotoxicosis, transient hypothyroidism, or transient thyrotoxicosis followed by transient hypothyroidism and return to euthyroidism (Figure 4.3) (113). Latter is the classic form.

\section{Pathophysiology}

It is an autoimmune disorder associated with TPO antibodies, thyroglobulin antibodies, lymphocyte dysregulation, complement activation, excess natural killer cell activity, high IgG1 and HLA DR3,4,5 (90).

The presence of other autoimmune disorders and previous history of postpartum thyroiditis also increase the risk (114)(115).

\section{Symptoms}

In thyrotoxic phase palpitations, fatigue, heat intolerance, and irritability/nervousness are common symptoms. 
Hypothyroid patient would complain of impaired concentration, carelessness, dry skin, poor memory, and decreased energy.

However both toxic and hypothyroid phases may be asymptomatic or present with subtle nonspecific symptoms.

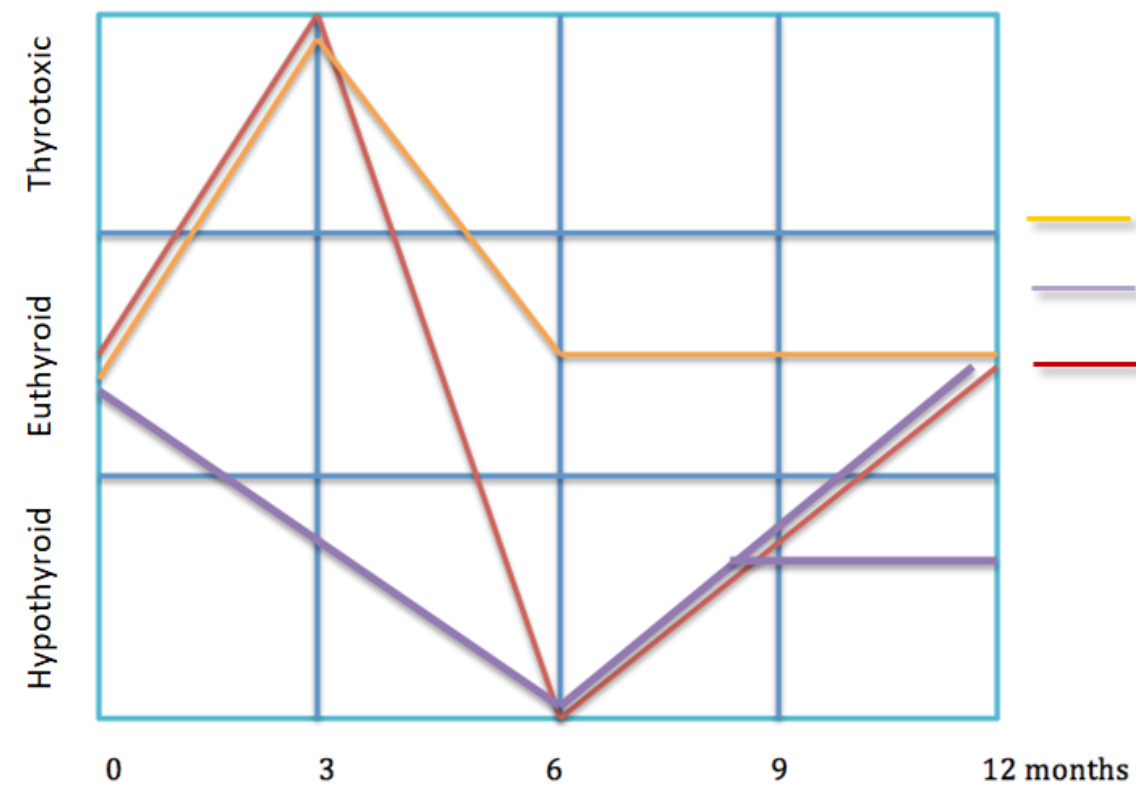

Figure 4.3. Clinical presentations of post-partum thyroiditis

\section{Table 4.9. Differentiation of post-partum thyroiditis and GD}

Feature

Graves disease

Post-partum thyroiditis

\begin{tabular}{lll}
\hline Timing & Majority occurs after 3 months from delivery & Majority occurs within 3 months postpartum \\
Prevalence & $0.2 \%$ & $4.1 \%$ \\
Unique clinical features & Goitre with a bruit, ophthalmopathy & - \\
TRAb & Positive & Negative \\
T3:T4 & High & Low \\
Thyroid uptake scan* & Increased uptake & Decreased uptake \\
\hline
\end{tabular}

*Thyroid uptake scan should not be performed in lactating mothers. TRAb: TSH receptor antibodies

\section{Management}

Management of post-partum thyroiditis is described in the algorithm in figure 4.4 . 


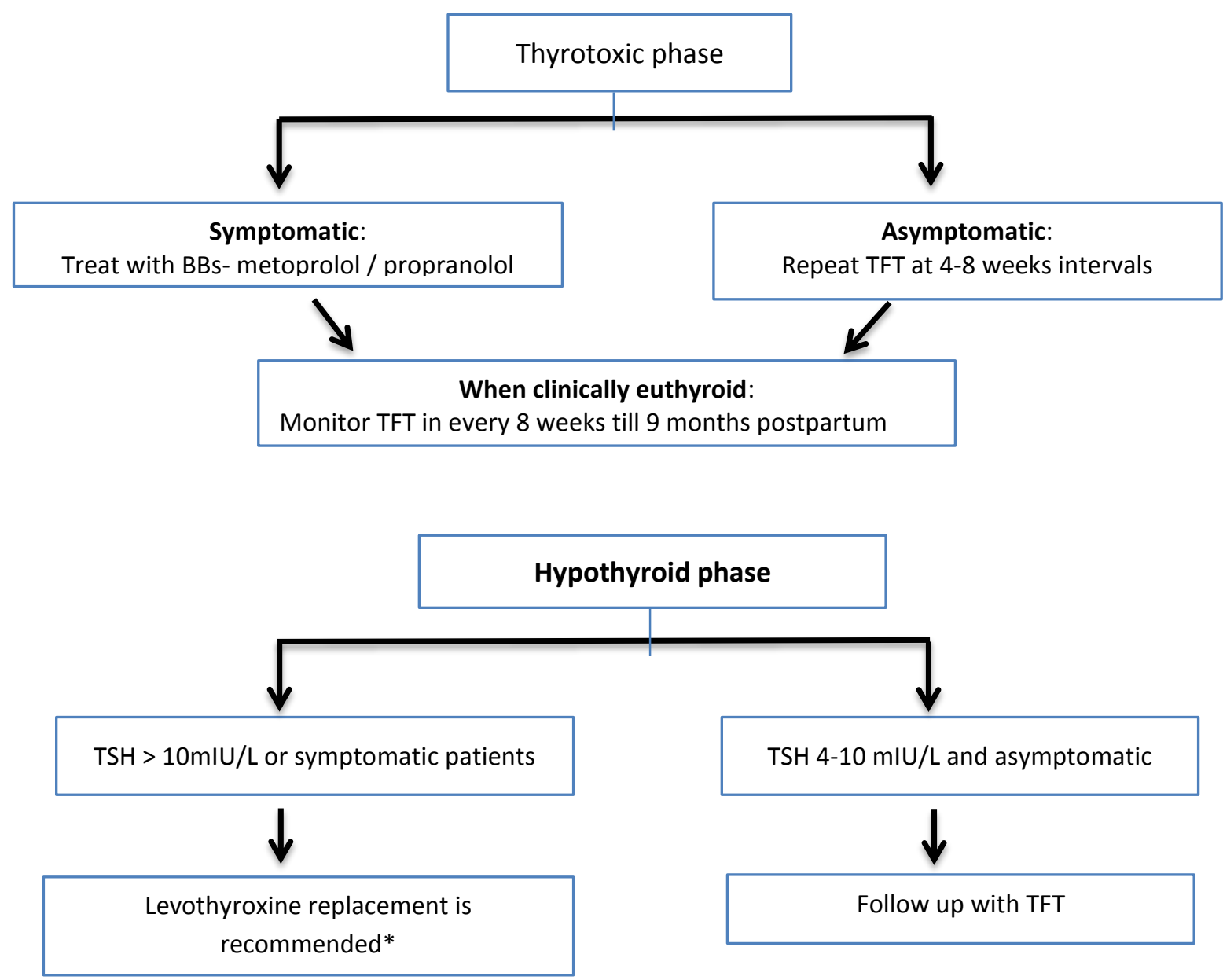

Figure 4.4. Management of different phases of post-partum thyroiditis

*A decision to tail off levothyroxine may be considered if not planning to conceive by 1 year postpartum.

\section{Key recommendations}

\section{Hypothyroidism in pregnancy}

Screen for hypothyroidism for routine indications as in non-pregnant populations (section 2.5, box 2.1). Use pregnancy specific reference ranges for diagnosis and monitoring (table 4.1).

Treat overt hypothyroidism with LT4. Starting dose in pregnancy is $2.33 \mu \mathrm{g} / \mathrm{kg} / \mathrm{day}$. For patients stably on levothyroxine prior to conception, increase the prepregnancy dose by $30 \%$.

Treatment of subclinical hypothyroidism should be decided considering TPO antibody status and TSH level (figure 4.2).
Monitor TFT monthly till 20 weeks and at least once around 30 weeks. Aim to maintain TSH in trimester specific normal range.

Reduce dose of levothyroxine to pre-pregnant stable dose or two-thirds of last trimester dose (if stabilized during pregnancy) following birth of the child in a female with overt hypothyroidism. Lower doses or withdrawal can be considered in subclinical hypothyroidism (table 4.5).

Reassess thyroid functions at six weeks post-partum.

Hypothyroidism, thyroid autoimmunity and fertility

Treatment of overt and subclinical hypothyroidism to achieve euthyroidism is recommended in females with subfertility 
There is no recommendation to treat euthyroid females with thyroid autoimmunity and subfertility

\section{Thyrotoxicosis in pregnancy}

Graves disease may first manifest during pregnancy. Gestational thyrotoxicosis (table 4.7) and post-partum thyroiditis (table 4.9) are important differentials to consider in first trimester and post-partum period respectively.

Beta blockers can be used for symptom control for a brief period. Avoid atenolol during pregnancy.

Graves disease is treated with ATDs (propylthiouracil up to 16th week, carbimazole thereafter) during pregnancy (table 4.8). Aim normal TSH and upper normal FT4 for pregnancy specific ranges. Monitor foetal heart rate and growth, especially if maternal TRAb titres are high.

RAI is absolutely contraindicated. Consider surgery (preferably in second trimester) in ATD failure or intolerance.

Gestational thyrotoxicosis (table 4.7) and post-partum thyroiditis is treated symptomatically with beta blockers (figure 4.4). Monitor thyroid functions in post-partum thyroiditis for progression to hypothyroidism.

\section{THYROID EMERGENCIES}

\subsection{Myxoedema coma}

Myxoedema coma is an endocrine emergency which occurs as the culmination of severe longstanding hypothyroidism or be precipitated by an acute event in a poorly controlled hypothyroidism.

Impaired mental status and hypothermia are hallmark features. Hypotension, bradycardia, hypoventilation, hyponatraemia and hypoglycaemia may occur.

Infection, myocardial infarction, cold exposure, surgery (116) or administration of sedative drugs are potential precipitating factors.

Coexisting adrenal insufficiency either due to autoimmune adrenal disease or hypothalamo-pituitary disease needs to be considered in patients presenting with myxoedema coma, as treatment with levothyroxine will precipitate an acute adrenal insufficiency.

Box 5.1. Management of myxoedema coma

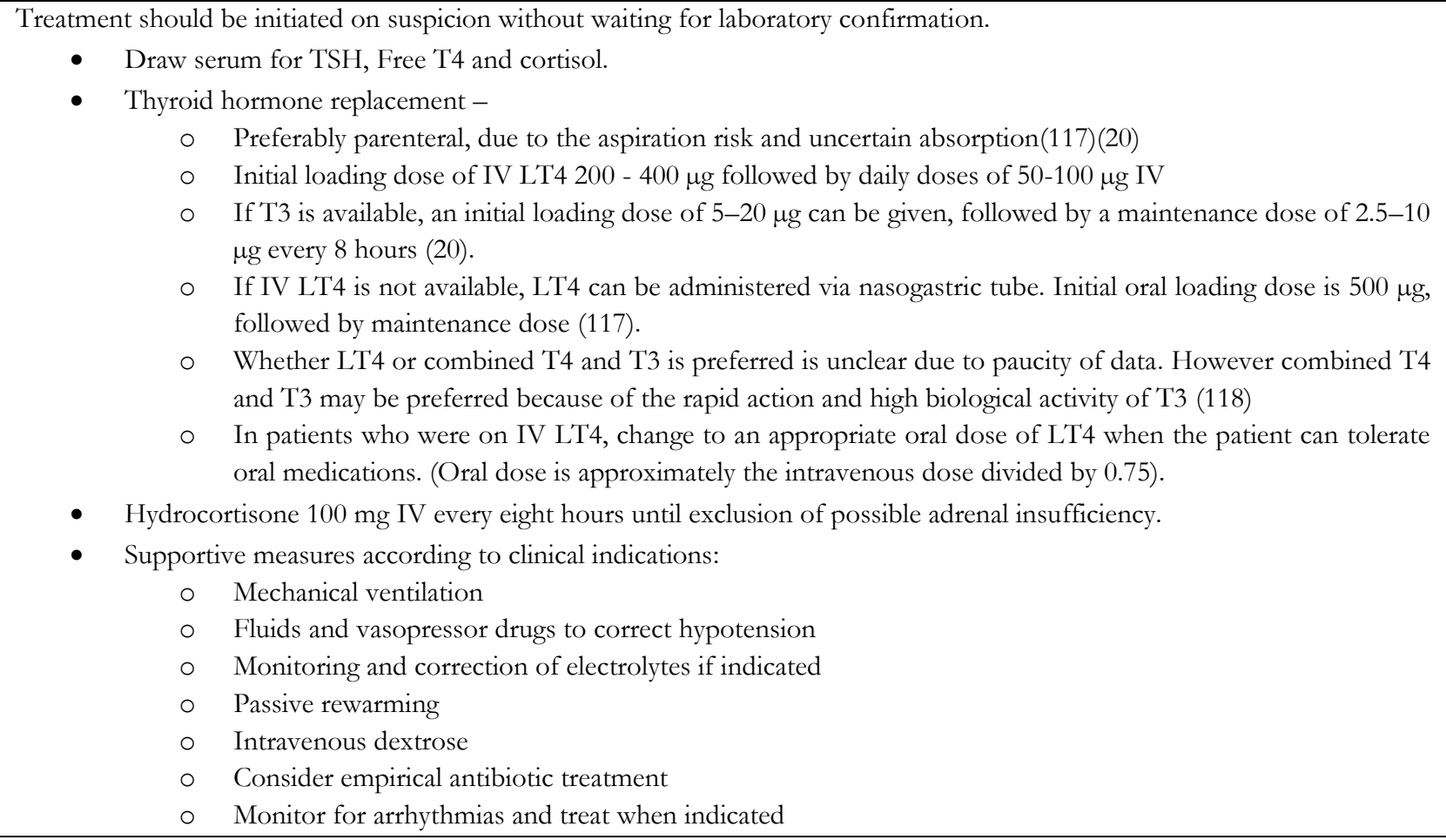




\subsection{Thyroid storm}

Thyroid storm is a rare disorder with multi-system involvement and high mortality (119).

In the past, the most common precipitating cause was thyroid surgery. Incompletely treated hyperthyroidism or interrupted drug therapy are the leading causes at present (120).

\subsubsection{Diagnosis}

Thyroid storm is clinical diagnosis and is assisted by Burch-Wartofsky Point Scale (BWPS) (Table 3) or Japanese Thyroid Association (JTA) categories of thyroid storm (120).

If diagnosis is suspected treatment should be commenced immediately to prevent increased risk of mortality.

\section{Table 5.1. Burch-Wartofsky Point Scale for diagnosis of thyrotoxic storm}

\begin{tabular}{|c|c|c|c|c|}
\hline System involvement & Score determined by severity & Distribution of sco & res & \\
\hline 1. Thermoregulatory dysfunction & $5-30$ & $\begin{array}{l}99.0-99.9 \\
100.0-100.9 \\
101.0-101.9-15 \text { 102-102.9 } \\
103.0-103.9 \\
>104\end{array}$ & $\begin{array}{c}5 \\
10 \\
20 \\
25 \\
30\end{array}$ & \\
\hline 2. Central nervous system dysfunction & $0-30$ & $\begin{array}{l}\text { Absent } \\
\text { Mild(agitation) } \\
\text { Moderate(delirium,psychosis } \\
\text { Severe(seizure, coma)- }\end{array}$ & & $\begin{array}{r}0 \\
10 \\
20 \\
30\end{array}$ \\
\hline 3. Cariovascular dysfunction-Heart rate & $5-25$ & $\begin{array}{l}100-109-5 \\
110-119-10 \\
120-129-15 \\
130-139-20 \\
>140-\quad 25\end{array}$ & & \\
\hline $\begin{array}{l}\text { 4. Cardiovascular dysfunction -Heart } \\
\text { failure }\end{array}$ & $0-15$ & $\begin{array}{l}\text { Absent- } 0 \\
\text { Mild - } 5 \\
\text { Moderate- } 10 \\
\text { Severe- } 20\end{array}$ & & \\
\hline $\begin{array}{l}\text { 5. Cardiovascular dysfunction-Atrial } \\
\text { Fibrillation }\end{array}$ & $0-10$ & $\begin{array}{l}\text { Absent- } 0 \\
\text { Present-10 }\end{array}$ & & \\
\hline $\begin{array}{l}\text { 6. Gastro-intestinal and hepatic } \\
\text { dysfunction }\end{array}$ & $0-20$ & $\begin{array}{l}\text { Absent }-0 \\
\text { Moderate- } 10 \\
\text { Severe(jaundice) }-20\end{array}$ & & \\
\hline 7. Precipitant history & $0-10$ & $\begin{array}{l}\text { Absent-0 } \\
\text { Present-10 }\end{array}$ & & \\
\hline
\end{tabular}

Adapted from Burch and Wartofsky(119)

A score of 45 or greater is highly suggestive of thyroid storm; a score of 25 to 44 is suggestive of impending storm, and a score below 25 is unlikely to represent thyroid storm. 


\subsubsection{Management of thyroid storm}

Management can be divided in to broad areas as outlined below in box 5.2 .
Patients who have survived thyroid storm should receive definitive therapy for their underlying hyperthyroidism to avoid any recurrence of this potentially fatal condition

Box 5.2. Management of thyroid storm

1. Ameliorate hyperadrenergic state

- Propranolol 40-80 mg orally every 6 hours or short acting BBs such as labetolol and esomolol are preferred

- When BBs are contraindicated, diltiazem can be used for rate control.

- In high output cardiac failure above agents should be used with caution.

2. Inhibit new TH synthesis

- Propylthiouracil 500 - $1000 \mathrm{mg}$ load and $200 \mathrm{mg}$ every 4 hours (also and inhibits peripheral conversion of T4 to T3)

3. Inhibition of peripheral conversion of $\mathrm{T} 4$ to $\mathrm{T} 3$

- IV hydrocortisone $300 \mathrm{mg}$ load and $100 \mathrm{mg} 8$ hourly (also corrects relative adrenal insufficiency)

4. Retard the release of pre-formed TH by iodine compounds

- Saturated solution of potassium -iodide (SSKI) 5 drops 6 hourly or Lugol's iodine solution 10 drops 8 hourly

- Start 1 hour after first ATD dose

5. Deplete TH pool by enhancing clearance through enterohepatic circulation

- Cholestyramine $4 \mathrm{~g}$ in 6 hourly

Other measures

- $\quad$ Consider ICU care

- Peripheral cooling, intra venous fluids and antipyretics

- Plasmapheresis

Note: Salicylates should be avoided as they increase the free TH and also possibly accelerate the metabolic rate.

\section{References}

1. Taylor PN, Albrecht D, Scholz A, Gutierrez-buey G, Lazarus JH, Dayan CM, et al. Global epidemiology of byperthyroidism and hypothyroidism. 2018; May;14(5):301316. doi: 10.1038/nrendo.2018.18. Epub 2018 Mar 23

2. Vanderpump MPJ, Tunbridge WMG, French JM, Appleton D, Bates D, Clark F, et al. The incidence of thyroid disorders in the community: A twenty-year follow-up of the Whickham Survey. Clin Endocrinol $(O x f)$. 1995;43(1):55-68.

3. Vanderpump MPJ, French JM, Appleton D, Tunbridge WMG, Kendall-Taylor P. The prevalence of hyperprolactinaemia and association with markers of autoimmune thyroid disease in survivors of the Whickham Survey cohort. Clin Endocrinol $(O x f)$. 1998;48(1):39-44.
4. Vanderpump MPJ. The epidemiology of thyroid disease. Br Med Bull. 2011;99(1):39-51.

5. Hollowell JG, Staehling NW, Dana Flanders W, Harry Hannon W, Gunter EW, Spencer CA, et al. Serum TSH, T4, and thyroid antibodies in the United States population (1988 to 1994): National Health and Nutrition Examination Survey (NHANES III). J Clin Endocrinol Metab. 2002;87(2):489-99.

6. Laurberg $\mathrm{P}$, pedersen $\mathrm{KM}$, vestergaard $\mathrm{H}$, sigurdsson G. High incidence of multinodular toxic goitre in the elderly population in a low iodine intake area vs. high incidence of Graves' disease in the young in a high iodine intake area: comparative surveys of thyrotoxicosis epidemiology in East- Jutland Denmark a. J Intern Med. 1991;229(5):415-20. 
7. Nyström HF, Jansson S, Berg G. Incidence rate and clinical features of hyperthyroidism in a long-term iodine sufficient area of Sweden (Gothenburg) 20032005. Clin Endocrinol (Oxf). 2013;78(5):768-76.

8. Korevaar TIM, Medici M, Visser TJ, Peeters RP. Thyroid disease in pregnancy: New insights in diagnosis and clinical management [Internet]. Vol. 13, Nature Reviews Endocrinology. Nature Publishing Group; 2017. p. 610-22. Available from: http://dx.doi.org/10.1038/nrendo.2017.93

9. Fernando RF, Chandrasinghe PC, Pathmeswaran AA. The prevalence of autoimmune thyroiditis after universal salt iodisation in Sri Lanka. Ceylon Med J. 2012;57(3):116-9.

10. Kahandawa S, Somasundaram NP, Ediriweera DS, Kusumsiri D, Ellawala S, Chandrika G, et al. Prevalence of thyroid dysfunction among type 2 diabetic patients attending the Diabetes Clinic, National Hospital of Sri Lanka. Sri Lanka J Diabetes Endocrinol Metab. 2014;4(1):43.

11. Haugen BR, Alexander EK, Bible KC, Doherty GM, Mandel SJ, Nikiforov YE, et al. 2015 American Thyroid Association Management Guidelines for Adult Patients with Thyroid Nodules and Differentiated Thyroid Cancer: The American Thyroid Association Guidelines Task Force on Thyroid Nodules and Differentiated Thyroid Cancer. Thyroid. 2016;26(1):1-133.

12. Sheehan MT. Biochemical testing of the thyroid: TSH is the best and, oftentimes, only test needed - A review for primary care. Vol. 14, Clinical Medicine and Research. 2016. p. 83-92.

13. Koulouri O, Moran C, Halsall D, Chatterjee K, Gurnell M. Pitfalls in the measurement and interpretation of thyroid function tests [Internet]. Vol. 27, Best Practice and Research: Clinical Endocrinology and Metabolism. Elsevier Ltd; 2013. p. 745-62. Available http://dx.doi.org/10.1016/j.beem.2013.10.003

14. Razvi S, Bhana S, Mrabeti S. Challenges in interpreting thyroid stimulating hormone results in the diagnosis of thyroid dysfunction. Vol. 2019, Journal of Thyroid Research. 2019.

15. Li D, Radulescu A, Shrestha RT, Root M, Karger AB, Killeen AA, et al. Association of Biotin Ingestion With Performance of Hormone and Nonhormone Assays in Healthy Adults. JAMA. 2017 Sep;318(12):1150-60.

16. Huber G, Staub JJ, Meier C, Mitrache C, Guglielmetti $\mathrm{M}$, Huber $\mathrm{P}$, et al. Prospective study of the spontaneous course of subclinical hypothyroidism: Prognostic value of thyrotropin, thyroid reserve, and thyroid antibodies. I Clin Endocrinol Metab. 2002;87(7):3221-6.

17. Stassi G, De Maria R. Autoimmune thyroid disease: new models of cell death in autoimmunity. Nat Rev Immunol. 2002 Mar;2(3):195-204.

18. Antonelli A, Benvenga S. Editorial: The association of other autoimmune diseases in patients with thyroid autoimmunity. Front Endocrinol (Lausanne). 2018;9(SEP):1-4.

19. Martin I Surks. Clinical manifestations of hypothyroidism. UpToDate. 2020 (last update $16^{\text {th }}$ July 2019. Accessed on 02nd March 2020). Available from; https://www.uptodate.com/contents/clinicalmanifestations-of-hypothyroidism/

20. Jonklaas J, Bianco AC, Bauer AJ, Burman KD, Cappola AR, Celi FS, et al. Guidelines for the treatment of hypothyroidism: Prepared by the American thyroid association task force on thyroid hormone replacement. Thyroid. 2014;24(12):1670-751.

21. Garber JR, Cobin RH, Gharib H, Hennessey J V., Klein I, Mechanick JI, et al. Clinical practice guidelines for hypothyroidism in adults: Cosponsored by the american association of clinical endocrinologists and the American thyroid association. , Endocrine Practice. 2012;18: 988-1028.

22. Santini F, Pinchera A, Marsili A, Ceccarini G, Castagna MG, Valeriano $R$, et al. Lean body mass is a major determinant of levothyroxine dosage in the treatment of thyroid diseases. J Clin Endocrinol Metab. 2005;90(1):124-7.

23. Hays MT, Nielsen KRK. Human thyroxine absorption: Age effects and methodological analyses. Thyroid. 1994;4(1):55-64.

24. Burmeister LA, Goumaz MO, Mariash $\mathrm{CN}$, Oppenheimer JH. Levothyroxine dose requirements for thyrotropin suppression in the treatment of differentiated thyroid cancer. J Clin Endocrinol Metab. 1992 Aug;75(2):344-50.

25. Gencer B, Collet TH, Virgini V, Bauer DC, Gussekloo J, Cappola AR, et al. Subclinical thyroid dysfunction and the risk of heart failure events an individual participant data analysis from 6 prospective cohorts. Circulation. 2012;126(9):1040-9.

26. Kabadi UM. "Subclinical hypothyroidism". Natural course of the syndrome during a prolonged follow-up study. Arch Intern Med. 1993 Apr;153(8):957-61.

27. Hak AE, Pols HAP, Visser TJ, Drexhage HA, Hofman A, Witteman JCM. Subclinical hypothyroidism is an independent risk factor for atherosclerosis and myocardial infarction in elderly 
women: The Rotterdam study. Ann Intern Med. 2000;132(4):270-8.

28. Chaker L, Baumgartner C, Ikram MA, Dehghan A, Medici M, Visser WE, et al. Subclinical thyroid dysfunction and the risk of stroke: a systematic review and meta-analysis. Eur J Epidemiol. 2014;29(11):791800 .

29. Biondi B, Cappola AR, Cooper DS. Subclinical Hypothyroidism: A Review. JAMA -. 2019;322(2):153-60.

30. Chung GE, Kim D, Kim W, Yim JY, Park MJ, Kim YJ, et al. Non-alcoholic fatty liver disease across the spectrum of hypothyroidism. J Hepatol [Internet]. 2012;57(1):150-6. Available from: http://dx.doi.org/10.1016/j.jhep.2012.02.027

31. Calsolaro V, Niccolai F, Pasqualetti G, Tognini S, Magno S, Riccioni T, et al. Hypothyroidism in the Elderly: Who Should Be Treated and How? J Endocr Soc. 2019;3(1):146-58.

32. Duntas LH, Yen PM. Diagnosis and treatment of hypothyroidism in the elderly. Endocrine [Internet]. 2019;66(1):63-9. Available from: http://dx.doi.org/10.1007/s12020-019-02067-9

33. Bauer DC, Ettinger B, Nevitt MC, Stone KL; Study of Osteoporotic Fractures Research Group. Risk for Fracture in Women with Low Serum Levels of thyroid-stimulating hormone. Ann Intern Med. 2001;134(7):561-568. doi:10.7326/0003-4819-134-7200104030-00009

34. Sawin CT, Geller A, Wolf PA, Belanger AJ, Baker E, Bacharach P, et al. Low serum thyrotropin concentrations as a risk factor for atrial fibrillation in older persons. N Engl J Med. 1994 Nov;331(19):1249_ 52.

35. Turner MR, Camacho X, Fischer HD, Austin PC, Anderson GM, Rochon PA, et al. Levothyroxine dose and risk of fractures in older adults: Nested casecontrol study. BMJ 2011;342(7805):1-9.

36. De Leo S, Lee SY, Braverman LE. Hyperthyroidism. Lancet. 2016;388(10047):906-918. doi:10.1016/S0140-6736(16)00278-6

37. Ross DS, Burch HB, Cooper DS, Greenlee MC, Laurberg P, Maia AL, et al. 2016 American Thyroid Association Guidelines for Diagnosis and Management of Hyperthyroidism and Other Causes of Thyrotoxicosis. Thyroid. 2016;26(10):1343-421.

38. Brent GA. Graves' Disease. N Engl J Med [Internet]. 2008;358(24):2594-605. Available from: https://doi.org/10.1056/NEJMcp0801880
39. Burch HB, Cooper DS. Management of graves disease a review. JAMA - JAm Med Assoc. 2015;314(23):2544-54.

40. Smith TJ, Hegedüs L. Graves' disease. N Engl J Med. 2016;375(16):1552-65.

41. Nishihara E, Ohye H, Amino N, Takata K, Arishima $\mathrm{T}$, Kudo T, et al. Clinical characteristics of 852 patients with subacute thyroiditis before treatment. Intern Med. 2008;47(8):725-9.

42. Martin FIR, Deam DR. Hyperthyroidism in elderly hospitalised patients: Clinical features and treatment outcomes. Med J Aust. 1996;164(4):200-3.

43. Amino N, Yabu Y, Miki T, Morimoto S, Kumahara $\mathrm{Y}$, Mori $\mathrm{H}$, et al. Serum ratio of triiodothyronine to thyroxine, and thyroxine-binding globulin and calcitonin concentrations in graves' disease and destruction- induced thyrotoxicosis. J Clin Endocrinol Metab. 1981;53(1):113-6.

44. Baral S, Shrestha PK, Pant V. Serum free T3 to free T4 ratio as a useful indicator for differentiating destruction induced thyrotoxicosis from graves' disease. J Clin Diagnostic Res. 2017;11(7):OC12-4.

45. Ceccarelli C, Bencivelli W, Vitti P, Grasso L, Pinchera A. Outcome of radioiodine-131 therapy in hyperfunctioning thyroid nodules: A 20 years' restrospective study. Clin Endocrinol $(O x f)$. 2005;62(3):331-5.

46. Sisson JC, Freitas J, McDougall IR, Dauer LT, Hurley JR, Brierley JD, et al. Radiation safety in the treatment of patients with thyroid diseases by radioiodine 131I: Practice recommendations of the american thyroid association. Thyroid. 2011;21(4):335-46.

47. Burch HB, Solomon BL, Cooper DS, Ferguson P, Walpert N, Howard R. The effect of antithyroid drug pretreatment on acute changes in thyroid hormone levels after 131I ablation for Graves' disease. J Clin Endocrinol Metab. 2001;86(7):3016-21.

48. Tamatea JAU, Conaglen J V., Elston MS. Response to Radioiodine Therapy for Thyrotoxicosis: Disparate Outcomes for an Indigenous Population. Int $J$ Endocrinol. 2016;2016.

49. Chaudhari NK. Influence of Neurotransmitters on GnRH release in Letrozole induced Polycystic Ovarian syndrome rat model. Endocr Abstr. 2015;37 EP659.

50. Erem C, Kandemir N, Hacihasanoglu A, Ersöz HÖ, Ukinc K, Kocak M. Radioiodine treatment of hyperthyroidism: Prognostic factors affecting outcome. Endocrine. 2004;25(1):55-60. 
51. Cepková J, Horáček J, Vižd’a J, Doležal J. Radioiodine treatment of Graves' disease - dose/response analysis. Acta Medica (Hradec Kralove) [Internet]. 2014;57(2):49-55. Available from: https://dx.doi.org/10.14712/18059694.2014.39

52. Yano Y, Sugino K, Akaishi J, Uruno T, Okuwa K, Shibuya $\mathrm{H}$, et al. Treatment of autonomously functioning thyroid nodules at a single institution: Radioiodine therapy, surgery, and ethanol injection therapy. Ann Nucl Med. 2011;25(10):749-54.

53. Greenspan BS, Siegel JA, Hassan A, Silberstein EB. There is no association of radioactive iodine treatment with cancer mortality in patients with hyperthyroidism. J Nucl Med. 2019;60(11):1500-1.

54. Kitahara CM, Berrington De Gonzalez A, Bouville A, Brill AB, Doody MM, Melo DR, et al. Association of Radioactive Iodine Treatment with Cancer Mortality in Patients with Hyperthyroidism. JAMA Intern Med. 2019;179(8):1034-42.

55. Lo CY, Kwok KF, Yuen PW. A prospective evaluation of recurrent laryngeal nerve paralysis during thyroidectomy. Arch Surg. 2000;135(2):204-7.

56. Joliat GR, Guarnero V, Demartines N, Schweizer V, Matter M. Recurrent laryngeal nerve injury after thyroid and parathyroid surgery. Med (United States). 2017;96(17).

57. Ritter K, Elfenbein D, Schneider DF, Chen H, Sippel RS. Hypoparathyroidism after total thyroidectomy: incidence and resolution. J Surg Res. 2015;197(2):348353. doi:10.1016/j.jss.2015.04.059.

58. Abraham-Nordling M, Byström K, Törring O, Lantz $\mathrm{M}$, Berg $\mathrm{G}$, Calissendorff $\mathrm{J}$, et al. Incidence of hyperthyroidism in Sweden. Eur $J$ Endocrinol. 2011;165(6):899-905.

59. Laurberg P, Berman DC, Pedersen IB, Andersen S, Carlé A. Incidence and clinical presentation of moderate to severe Graves' orbitopathy in a Danish population before and after iodine fortification of salt. J Clin Endocrinol Metab. 2012;97(7):2325-32.

60. Tanda ML, Piantanida E, Liparulo L, Veronesi G, Lai A, Sassi L, et al. Prevalence and natural history of graves' orbitopathy in a large series of patients with newly diagnosed graves' hyperthyroidism seen at a single center. J Clin Endocrinol Metab. 2013;98(4):14439 .

61. Eckstein AK, Plicht M, Lax H, Neuhäuser M, Mann $\mathrm{K}$, Lederbogen S, et al. Thyrotropin receptor autoantibodies are independent risk factors for graves' ophthalmopathy and help to predict severity and outcome of the disease. J Clin Endocrinol Metab. 2006;91(9):3464-70.
62. Bahn RS. Graves' Ophthalmopathy. N Engl J Med [Internet]. 2010 Feb 25;362(8):726-38. Available from: https://doi.org/10.1056/NEJMra0905750

63. Burch HB, Wartofsky L. Graves' ophthalmopathy: Current concepts regarding pathogenesis and management. Endocr Rev. 1993;14(6):747-93.

64. Mourits MP, Prummel MF, Wiersinga WM, Koornneef L. Clinical activity score as a guide in the management of patients with Graves' ophthalmopathy. Clin Endocrinol (Oxf). 1997;47(1):914.

65. Bartalena L, Baldeschi L, Boboridis K, Eckstein A, Kahaly GJ, Marcocci C, et al. The 2016 European Thyroid Association/European Group on Graves' Orbitopathy Guidelines for the Management of Graves' Orbitopathy. Eur Thyroid J. 2016;5(1):9-26.

66. Wiersinga WM. Smoking and thyroid. Clin Endocrinol (Oxf). 2013;79(2):145-51.

67. Bartalena L, Martino E, Marcocci C, Bogazzi F, Panicucci M, Velluzzi F, et al. More on smoking habits and Graves' ophthalmopathy. J Endocrinol Invest. 1989;12(10):733-7.

68. Bartalena L, Marcocci C, Bogazzi F, Manetti L, Tanda M L DE. Relation Between Therapy for Hyperthyroidism and the Course. $N$ Engl J Med. 1998;338(2):73-8.

69. Bartalena L, Marcocci C, Tanda ML, et al. Cigarette smoking and treatment outcomes in Graves ophthalmopathy. Ann Intern Med. 1998;129(8):632635. doi:10.7326/0003-4819-129-8-199810150-00010

70. Pfeilschifter J, Ziegler R. Smoking and endocrine ophthalmopathy: Impact of smoking severity and current vs lifetime cigarette consumption. Clin Endocrinol (Oxf). 1996;45(4):477-81.

71. Acharya SH, Avenell A, Philip S, Burr J, Bevan JS, Abraham P. Radioiodine therapy (RAI) for Graves' disease (GD) and the effect on ophthalmopathy: A systematic review. Clin Endocrinol (Oxf). 2008;69(6):943-50.

72. Vannucchi G, Campi I, Covelli D, Dazzi D, Currò N, Simonetta S, et al. Graves' orbitopathy activation after radioactive iodine therapy with and without steroid prophylaxis. J Clin Endocrinol Metab. 2009;94(9):33816.

73. Lai A, Sassi L, Compri E, Marino F, Sivelli P, Piantanida E, et al. Lower dose prednisone prevents radioiodine-associated exacerbation of initially mild or absent Graves' orbitopathy: A retrospective cohort study. J Clin Endocrinol Metab. 2010;95(3):1333-7. 
74. Sheck L. Selenium and the course of mild graves' orbitopathy. N Engl J Med. 2011;365(8):770.

75. Zang S, Ponto KA, Kahaly GJ. Intravenous glucocorticoids for graves' orbitopathy: Efficacy and morbidity. J Clin Endocrinol Metab. 2011;96(2):320-32.

76. van Geest RJ, Sasim I V., Koppeschaar HPF, Kalmann R, Stravers SN, Bijlsma WR, et al. Methylprednisolone pulse therapy for patients with moderately severe Graves' orbitopathy: A prospective, randomized, placebo-controlled study. Eur J Endocrinol. 2008;158(2):229-37.

77. Stiebel-Kalish H, Robenshtok E, Hasanreisoglu M, Ezrachi D, Shimon I, Leibovici L. Treatment modalities for graves' ophthalmopathy: Systematic review and metaanalysis. J Clin Endocrinol Metab. 2009;94(8):2708-16.

78. Currò N, Covelli D, Vannucchi G, Campi I, Pirola G, Simonetta S, et al. Therapeutic outcomes of high-dose intravenous steroids in the treatment of dysthyroid optic neuropathy. Thyroid. 2014;24(5):897-905.

79. Wakelkamp IMMJ, Baldeschi L, Saeed P, Mourits MP, Prummel MF, Wiersinga WM. Surgical or medical decompression as a first-line treatment of optic neuropathy in Graves' ophthalmopathy? A randomized controlled trial. Clin Endocrinol (Oxf). 2005;63(3):323-8.

80. Kahaly GJ, Riedl M, König J, Pitz S, Ponto K, Diana $\mathrm{T}$, et al. Mycophenolate plus methylprednisolone versus methylprednisolone alone in active, moderateto-severe Graves' orbitopathy (MINGO): a randomised, observer-masked, multicentre trial. Lancet Diabetes Endocrinol. 2018;6(4):287-98.

81. Mourits MP, van Kempen-Harteveld ML, García MB, Koppeschaar HP, Tick L, Terwee CB. Radiotherapy for Graves' orbitopathy: randomised placebocontrolled study. Lancet. 2000;355(9214):1505-1509. doi: 10.1016/S0140-6736(00)02165-6

82. Prummel MF, Terwee CB, Gerding MN, Baldeschi L, Mourits MP, Blank L, et al. A Randomized Controlled Trial of Orbital Radiotherapy Versus Sham Irradiation in Patients with Mild Graves' Ophthalmopathy. J Clin Endocrinol Metab. 2004;89(1):15-20.

83. Bartalena L, Marcocci C, Tanda ML, et al. Cigarette smoking and treatment outcomes in Graves ophthalmopathy. Ann Intern Med. 1998;129(8):632635. doi:10.7326/0003-4819-129-8-199810150-00010

84. Salvi M, Vannucchi G, Currò N, Campi I, Covelli D, Dazzi D, et al. Efficacy of B-cell targeted therapy with rituximab in patients with active moderate to severe graves' orbitopathy: A randomized controlled study. $J$ Clin Endocrinol Metab. 2015;100(2):422-31.
85. Stan MN, Garrity JA, Leon BGC, Prabin T, Bradley EA, Bahn RS. Randomized controlled trial of rituximab in patients with graves' orbitopathy. J Clin Endocrinol Metab. 2015;100(2):432-41.

86. Smith TJ, Kahaly GJ, Ezra DG, Fleming JC, Dailey RA, Tang RA, et al. Teprotumumab for thyroidassociated ophthalmopathy. $N$ Engl $J$ Med. 2017;376(18):1748-61.

87. Fatourechi V, Aniszewski JP, Fatourechi GZE, Atkinson EJ, Jacobsen SJ. Clinical features and outcome of subacute thyroiditis in an incidence cohort: Olmsted County, Minnesota, study. J Clin Endocrinol Metab. 2003;88(5):2100-5.

88. Benbassat CA, Olchovsky D, Tsvetov G, Shimon I. Subacute thyroiditis: Clinical characteristics and treatment outcome in fifty-six consecutive patients diagnosed between 1999 and 2005. J Endocrinol Invest. 2007;30(8):631-5.

89. Kubota S, Nishihara E, Kudo T, Ito M, Amino N, Miyauchi A. Initial treatment with $15 \mathrm{mg}$ of prednisolone daily is sufficient for most patients with subacute thyroiditis in Japan. Thyroid. 2013;23(3):269_ 72.

90. Alexander EK, Pearce EN, Brent GA, Brown RS, Chen H, Dosiou C, et al. 2017 Guidelines of the American Thyroid Association for the Diagnosis and Management of Thyroid Disease during Pregnancy and the Postpartum. Thyroid [Internet]. 2017 6;27(3):315-89. Available from: https://doi.org/10.1089/thy.2016.0457

91. Cappola A R CBM. Thyroid Function Test Abnormalities During Pregnancy. JAMA - J Am Med Assoc. 2019;322(7):617-9.

92. Dickens LT, Cifu AS, Cohen RN. Diagnosis and Management of Thyroid Disease during Pregnancy and the Postpartum Period. JAMA - J Am Med Assoc. 2019;321(19):1928-9.

93. Laurberg P, Andersen SL. Endocrinology in Pregnancy: Pregnancy and the incidence, diagnosing and therapy of Graves' disease, Eur J Endocrinol, 2016;175:R219-30.

94. Liyanarachchi K D, Muthukuda D T, Liyanage U A, Jayatissa R, Subasinghe L T, Pradeep A V K H, Colombage D D E, Ranasinghe L D, Lyanarachchi N $\mathrm{P}$, Ranasinghe H A S K, Lekamwasm S SNP. Trimester-specific thyroid hormone reference data in Sri Lanka. Sri Lanka J Diabetes, Endocrinol Metab. 2019;9(2):29.

95. Rao M, Zeng Z, Zhou F, Wang H, Liu J, Wang R, et al. Effect of levothyroxine supplementation on pregnancy loss and preterm birth in women with 
subclinical hypothyroidism and thyroid autoimmunity: A systematic review and meta-analysis. Hum Reprod Update. 2019;25(3):344-61.

96. Bekkering GE, Agoritsas T, Lytvyn L, Heen AF, Feller M, Moutzouri E, et al. Thyroid hormones treatment for subclinical hypothyroidism: A clinical practice guideline. BMJ. 2019;365:1-9.

97. Jansen TA, Korevaar TIM, Mulder TA, White T, Muetzel RL, Peeters RP, et al. Maternal thyroid function during pregnancy and child brain morphology: a time window-specific analysis of a prospective cohort. Lancet Diabetes Endocrinol [Internet]. 2019;7(8):629-37. Available from: http://dx.doi.org/10.1016/S2213-8587(19)30153-6

98. Lazarus J, Brown RS, Daumerie C, HubalewskaDydejczyk A, Negro R, Vaidya B. 2014 European Thyroid Association Guidelines for the Management of Subclinical Hypothyroidism in Pregnancy and in Children. Eur Thyroid J. 2014;3(2):76-94.

99. Yassa L, Marqusee E, Fawcett R, Alexander EK. Thyroid hormone early adjustment in pregnancy (the THERAPY) trial.J Clin Endocrinol Metab. 2010;95(7):3234-3241. doi:10.1210/jc.2010-0013

100. Morreale De Escobar G, Obregon MJ, Escobar Del Rey F. Clinical perspective: Is neuropsychological development related to maternal hypothyroidism or to maternal hypothyroxinemia? J Clin Endocrinol Metab. 2000;85(11):3975-87.

101. Stagnaro-Green A. Postpartum management of women begun on levothyroxine during pregnancy. Front Endocrinol (Lausanne). 2015;6(NOV):1-5.

102. Caixàs A, Albareda M, García-Patterson A, Rodríguez-Espinosa J, De Leiva A, Corcoy R. Postpartum thyroiditis in women with hypothyroidism antedating pregnancy? J Clin Endocrinol Metab. 1999;84(11):4000-5.

103. Argatska A, Nonchev B, Orbetzova M, Pehlivanov B. Postpartum thyroid dysfunction in women with autoimmune thyroiditis. Gynecol Endocrinol. 2016;32(5):379-82.

104. Galofré JC, Haber RS, Mitchell AA, Pessah R, Davies TF. Increased postpartum thyroxine replacement in Hashimoto's thyroiditis. Thyroid. 2010;20(8):901-8.

105. Shields BM, Knight BA, Hill A V., Hattersley AT, Vaidya B. Five-Year follow-Up for women with subclinical hypothyroidism in pregnancy. J Clin Endocrinol Metab. 2013;98(12):1941-5.

106. Smith A, Eccles-Smith J, D'Emden M, Lust K. Thyroid disorders in pregnancy and postpartum. Aust Prescr. 2017;40(6):214-9.
107. Korevaar TIM, Mínguez-Alarcón L, Messerlian C, De Poortere RA, Williams PL, Broeren MA, et al. Association of Thyroid Function and Autoimmunity with Ovarian Reserve in Women Seeking Infertility Care. Thyroid. 2018;28(10):1349-58.

108. Dhillon-Smith RK, Middleton LJ, Sunner KK, Cheed $\mathrm{V}$, Baker K, Farrell-Carver S, et al. Levothyroxine in women with thyroid peroxidase antibodies before conception. N Engl J Med. 2019;380(14):1316-25.

109. Andersen SL, Olsen J, Laurberg P. Antithyroid drug side effects in the population and in pregnancy. J Clin Endocrinol Metab. 2016;101(4):1606-14.

110. Tanaka K, Tanaka H, Kamiya C, Katsuragi S, Sawada M, Tsuritani M, et al. Beta-blockers and fetal growth restriction in pregnant women with cardiovascular disease. Circ J. 2016;80(10):2221-6.

111. Kahaly GJ, Bartalena L, Hegedüs L, Leenhardt L, Poppe K, Pearce SH. 2018 European thyroid association guideline for the management of graves' hyperthyroidism. Eur Thyroid J. 2018;7(4):167-86.

112. Nicholson WK, Robinson KA, Smallridge RC, Ladenson PW, Powe NR. Prevalence of postpartum thyroid dysfunction: A quantitative review. Thyroid. 2006;16(6):573-82.

113. Stagnaro-Green A. Clinical review 152: Postpartum thyroiditis. J Clin Endocrinol Metab. 2002;87(9):4042-7.

114. Gerstein HC. Incidence of postpartum thyroid dysfunction in patients with type I diabetes mellitus. Ann Intern Med. 1993;118(6):419-23.

115. Lazarus JH. Clinical aspects of recurrent postpartum thyroiditis. Br J Gen Pract. 1997;47(418):305-8.

116. Yafit D, Carmel-Neiderman NN, Levy N, Abergel A, Niv A, Yanko-Arzi R, et al. Postoperative myxedema coma in patients undergoing major surgery: Case series. Auris Nasus Larynx. 2019 Aug;46(4):605-8.

117. Dutta P, Bhansali A, Masoodi S, Bhadada S, Sharma N, Rajput R. Predictors of outcome in myxoedema coma: A study from a tertiary care centre. Crit Care. 2008;12(1):1-8.

118. Zhu Y, Qiu W, Deng M, Zhu X. Myxedema coma. Medicine (Baltimore). 2017;96(21):e6952.

119. Burch HB, Wartofsky L. Life-threatening thyrotoxicosis. Thyroid storm. Endocrinol Metab Clin North Am. 1993;22(2):263-77.

120. Chiha M, Samarasinghe S, Kabaker AS. Thyroid storm: An updated review. I Intensive Care Med. 2015;30(3):131-40. 